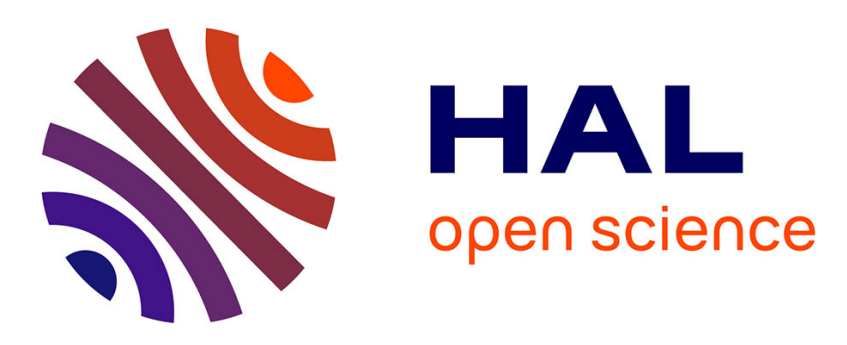

\title{
Effects of acute and chronic exercise on sarcolemmal MCT1 and MCT4 contents in human skeletal muscles: current status
}

Claire Thomas, David A Bishop, Karen Lambert, Jacques Mercier, George A Brooks

\section{To cite this version:}

Claire Thomas, David A Bishop, Karen Lambert, Jacques Mercier, George A Brooks. Effects of acute and chronic exercise on sarcolemmal MCT1 and MCT4 contents in human skeletal muscles: current status. AJP - Regulatory, Integrative and Comparative Physiology, 2012, 302, pp.1 - 14. 10.1152/ajpregu.00250.2011 . hal-01565188

\section{HAL Id: hal-01565188 https://hal-insep.archives-ouvertes.fr/hal-01565188}

Submitted on 19 Jul 2017

HAL is a multi-disciplinary open access archive for the deposit and dissemination of scientific research documents, whether they are published or not. The documents may come from teaching and research institutions in France or abroad, or from public or private research centers.
L'archive ouverte pluridisciplinaire HAL, est destinée au dépôt et à la diffusion de documents scientifiques de niveau recherche, publiés ou non, émanant des établissements d'enseignement et de recherche français ou étrangers, des laboratoires publics ou privés. 


\title{
Effects of acute and chronic exercise on sarcolemmal MCT1 and MCT4
}

\section{contents in human skeletal muscles: current status}

\author{
Claire Thomas, ${ }^{1,2,3}$ David J. Bishop, ${ }^{4,5}$ Karen Lambert, ${ }^{1}$ Jacques Mercier, ${ }^{1,6}$ and George A. Brooks ${ }^{7}$ \\ ${ }^{1}$ Institut National de la Santé et de la Recherche Médicale, U1046 "Physiologie et Médecine expérimentale du cour et des \\ muscles", Montpellier, France; ' ${ }^{2}$ niversité Evry Val d'Essonne, Unité de Formation et de Recherche des Sciences \\ fondamentales et appliquées, Département des sciences et techniques des activités physiques et sportives, Evry, France; \\ ${ }^{3}$ Institut national du sport, de l'Expertise et de la Performance, Service Recherche, Paris, France; ${ }^{4}$ Institute of Sport, \\ Exercise and Active Living and ${ }^{5}$ School of Sport and Exercise Science, Victoria University, Melbourne, Australia; ${ }^{6}$ Le Centre \\ Hospitalier Universitaire, Montpellier, France; and ${ }^{7}$ Integrative Biology, University of California, Berkeley, California, USA
}

Submitted 9 May 2011; accepted in final form 14 October 2011

\begin{abstract}
Thomas C, Bishop DJ, Lambert K, Mercier J, Brooks GA. Effects of acute and chronic exercise on sarcolemmal MCT1 and MCT4 contents in human skeletal muscles: current status. Am J Physiol Regul Integr Comp Physiol 302: R1-R14, 2012. First published October 19, 2011; doi:10.1152/ajpregu.00250.2011.-Two lactate/proton cotransporter isoforms (monocarboxylate transporters, MCT1 and MCT4) are present in the plasma (sarcolemmal) membranes of skeletal muscle. Both isoforms are symports and are involved in both muscle $\mathrm{pH}$ and lactate regulation. Accordingly, sarcolemmal MCT isoform expression may play an important role in exercise performance. Acute exercise alters human MCT content, within the first $24 \mathrm{~h}$ from the onset of exercise. The regulation of MCT protein expression is complex after acute exercise, since there is not a simple concordance between changes in mRNA abundance and protein levels. In general, exercise produces greater increases in MCT1 than in MCT4 content. Chronic exercise also affects MCT1 and MCT4 content, regardless of the initial fitness of subjects. On the basis of cross-sectional studies, intensity would appear to be the most important factor regulating exercise-induced changes in MCT content. Regulation of skeletal muscle MCT1 and MCT4 content by a variety of stimuli inducing an elevation of lactate level (exercise, hypoxia, nutrition, metabolic perturbations) has been demonstrated. Dissociation between the regulation of MCT content and lactate transport activity has been reported in a number of studies, and changes in MCT content are more common in response to contractile activity, whereas changes in lactate transport capacity typically occur in response to changes in metabolic pathways. Muscle MCT expression is involved in, but is not the sole determinant of, muscle $\mathrm{H}^{+}$and lactate anion exchange during physical activity.
\end{abstract}

lactate transport capacity; monocarboxylate transporters; training

SEVERAL LACTATE/PROTON COTRANSPORTER [monocarboxylate (lactate/pyruvate) transporter: $\mathrm{MCT}]$ isoforms are expressed in mammalian skeletal muscle, but, of those, MCT1 and MCT4 are the most prevalent. Since 1996, interest has focused on the effects of acute and chronic exercise on the membrane content of these two isoforms. This article will review recent progress in our understanding of the importance of lactate/proton cotransporters in the regulation of skeletal muscle metabolism and the effects of acute and chronic exercise on MCT content. In addition, we will review evidence investigating the cellular and molecular mechanisms responsible for changes in MCT content in response to contractile activity and changes in metabolic pathways.

Address for reprint requests and other correspondence: C. Thomas, Université d'Evry Val d'Essonne, Département STAPS, UFR des Sciences fondamentales et appliquées, Bvd F. Mitterrand, 91025 Evry cedex, France (e-mail: claire.thomas@univ-evry.fr).
Sarcolemmal Lactate/Proton Cotransporters in Skeletal Muscle

Metabolism and exchange of lactate. During heavy exercise, the rapid increase in the energy demand of contracting skeletal muscles is associated with an increase in glycolysis and the subsequent production and accumulation of lactate and proton (for review, see Ref. 128). To maintain a fast glycolytic flux during exercise, lactate production is catalyzed by the M-enriched lactate dehydrogenase isoforms (i.e., M4, M3H isoforms of LDH), which prevents pyruvate accumulation and, more importantly, maintains the supply of the proton-electron transporter nicotinamide adenine dinucleotide $\left(\mathrm{NAD}^{+}\right)$to glycolysis (see Ref. 68). Thus, lactate production favors the recycling of NADH from glycolysis, allowing the production of two ATP molecules per molecule of glucose utilized in glycolysis.

Although lactate was originally considered a "waste product," oxidative muscle fibers can take up lactate from the circulation, or lactate released from neighboring fibers. Hence, 
the subsequent metabolic use of intramuscular lactate results in ATP production without conversion to glucose in the liver. The pathway of intramuscular lactate disposal involves conversion to pyruvate and subsequent entry into the Krebs cycle, in which pyruvate can be oxidized $(27,141)$. Glyconeogenesis from lactate has been observed in human skeletal muscles (for review, see Ref. 47), in IIa and IIb rabbit (38) and rat (101) muscle fibers, but this conversion is negligible in type I fibers. Lactate also competes successfully with glucose as a carbohydrate fuel source in skeletal muscle, thus sparing blood glucose for use by other tissues during exercise $(91,107)$. Because of the difficulty in accessing the intracardiac circulation, there are limited data on the metabolic use of lactate by the heart. However, the available data (53) clearly show that during leg exercise in humans, lactate becomes the major fuel source for the heart. Indeed, net carbohydrate fuel is transferred from the legs to the heart during human exercise.

Because of the widely acknowledged importance of lactate as an energy source, contemporary reviewers often overlook the first demonstrated example of lactate use during exercise, that of Cori cycle activity to support glycemia via gluconeogenesis from lactate (22). However, by means of dual isotope tracers (49), monitoring of secondary labeling of glucose from infused ${ }^{13} \mathrm{C}$-labeled lactate (12), and mass isotopomer discrimination analysis (146), it is clear that during exercise lactate is by far the most important gluconeogenic precursor in humans during exercise, as it is in fasting (106). Thus, lactate is not only a compound that accumulates in various compartments during intense muscle activity, but it is also an important intermediary metabolite serving as an important link between energy metabolism in different tissues.

Lactate/proton cotransporters. In the 1970s, a saturation phenomenon was observed for lactate transport from exercising human skeletal muscle to the blood compartment $(62,66)$; it was subsequently reported that muscle lactate uptake also displayed a saturation effect $(67,68,129,130)$. A monocarboxylate transporter family, which mediates the 1:1 transmembrane cotransport of lactate and protons via a facilitated diffusion mechanism was first identified in red blood cells in the early $70 \mathrm{~s}$ by Halestrap and Denton (57), and later in skeletal frog muscle (93) and cardiac myocytes (121). Subsequently, different studies have determined the molecular identity of these MCTs $(51,120,123,150)$. The MCT family currently comprises 14 members $(58,102,109)$. MCT distribution is ubiquitous, but intracellular distribution varies among the different cell types (e.g., plasma membrane, mitochondrial membrane, peroxisome) $(23,95)$, although this distribution is not universally accepted (34). In skeletal muscle, the most important and well-described isoforms are MCT1 and MCT4 (19).

Lactate/proton cotransport is bidirectional, which means that these transporters facilitate lactate flux, relative to lactate concentration and the proton gradient, either into or out of the skeletal muscle $(30,68,70,100)$, according to the cell-to-cell "lactate shuttle" (27). This cell-to-cell lactate shuttle (27) provides the basic framework for the understanding of lactate metabolism and exchange. In the context of this review, MCTs play crucial roles in the lactate shuttle by facilitating the release and uptake of lactate by diverse tissues. Without the MCTs, lactate could not be as rapidly exchanged between tissue compartments, under conditions ranging from postprandial to sustained exercise $(31,37,58,149)$. In addition to lactate,
MCTs can also transport other monocarboxylates (pyruvate, acetate, propionate, and butyrate) and keto acids derived by transamination (alpha-keovalerate and alpha-ketoisocaproate), which have important metabolic roles (120). These transporters are, therefore, important for the regulation of cellular $\mathrm{pH}$ and lactate exchange, and play a significant role in the coordination of metabolism.

MCT1 has been found predominantly in oxidative human muscles $(r=0.66, P<0.01)$, and only in small amounts in glycolytic human muscles (119), whereas MCT4 has not been demonstrated to be correlated with fiber type, and to present large interindividual variations in humans $(39,119)$. The $K_{\mathrm{m}}$ value (an indicator of the affinity of the transporter protein for lactate; a low $K_{\mathrm{m}}$ value suggests a high affinity) of MCT1 $[3.5-8.3 \mathrm{mM}(21,25,37)]$ is lower than that of MCT4 [25-31 $\mathrm{mM}(25,37)]$, indicating a higher affinity of MCT1 for lactate compared with MCT4. With high lactate transport capacity and low affinity, MCT4 seems suited to play a role in the extrusion of lactate from glycolytic fibers (150). In addition, a high $K_{\mathrm{m}}$ (>100 mM) for pyruvate in glycolytic tissues (37) has to be mentioned. Indeed, this prevents loss of pyruvate, which would be a disaster for glycolytic fibers, since $\mathrm{NAD}^{+}$could no longer be regenerated by conversion of pyruvate to lactate, and thus, glycolysis would stop. Furthermore, in contrast, its high affinity for lactate and greater expression in more oxidative fibers strongly suggests that a key physiological role of MCT1 is to take up lactate from the circulation (24).

Both MCT1 and MCT4 contents have been reported to be associated with net muscle lactate release during submaximal exercise in humans $(21,39)$. Although MCT1 and MCT4 are coexpressed in muscle $(10,39)$, only MCT1 appears to contribute to increased metabolic use of lactate after muscle activity, by facilitating lactate influx into myocytes and cardiocytes (39). This conclusion is supported by studies reporting correlations between maximal muscle oxidative capacity and MCT1 content in both rats (98) and humans (39); however, this relationship between muscle oxidative capacity and MCT expression has not been observed in all studies (144). This trend for a dissociation between oxidative metabolism and lactate transport exchange is also in agreement with results obtained after high-intensity training $(77,116,131)$, endurance training (131), or a single, prolonged exercise bout in humans (55). For further information on the role and characterization of the different isoforms of MCT, and the integration of lactate metabolism in the lactate shuttle, the reader is referred to previous reviews $(26,27,54,68,74)$.

Cellular regulation: role of the $\mathrm{pH}$ gradient in regulating lactate transport activity during exercise. During high-intensity exercise, the production of lactate is associated with an increase in protons $\left(\mathrm{H}^{+}\right)$(i.e., a decrease in muscle $\left.\mathrm{pH}\right)(64$, 92). The management of muscle $\mathrm{H}^{+}$produced during exercise occurs via intracellular buffering (proteins and phosphates, and metabolic buffering) (16), and also via a number of different transport systems (71) (Fig. 1). MCT1 and MCT4 play important roles in the regulation of intracellular $\mathrm{pH}$ during highintensity exercise (75), since they mediate most, but not all, of the $\mathrm{H}^{+}$efflux $(69,71,72)$; other systems, such as the sarcolemmal sodium-hydrogen exchanger, are also activated during exercise. Nonetheless, during exercise, the lactate $/ \mathrm{H}^{+}$removal via MCTs exceeds the sum of the $\mathrm{H}^{+}$removal via the $\mathrm{Na}^{+} / \mathrm{H}^{+}$ exchanger and the bicarbonate-dependent system $(68,72,117)$. 


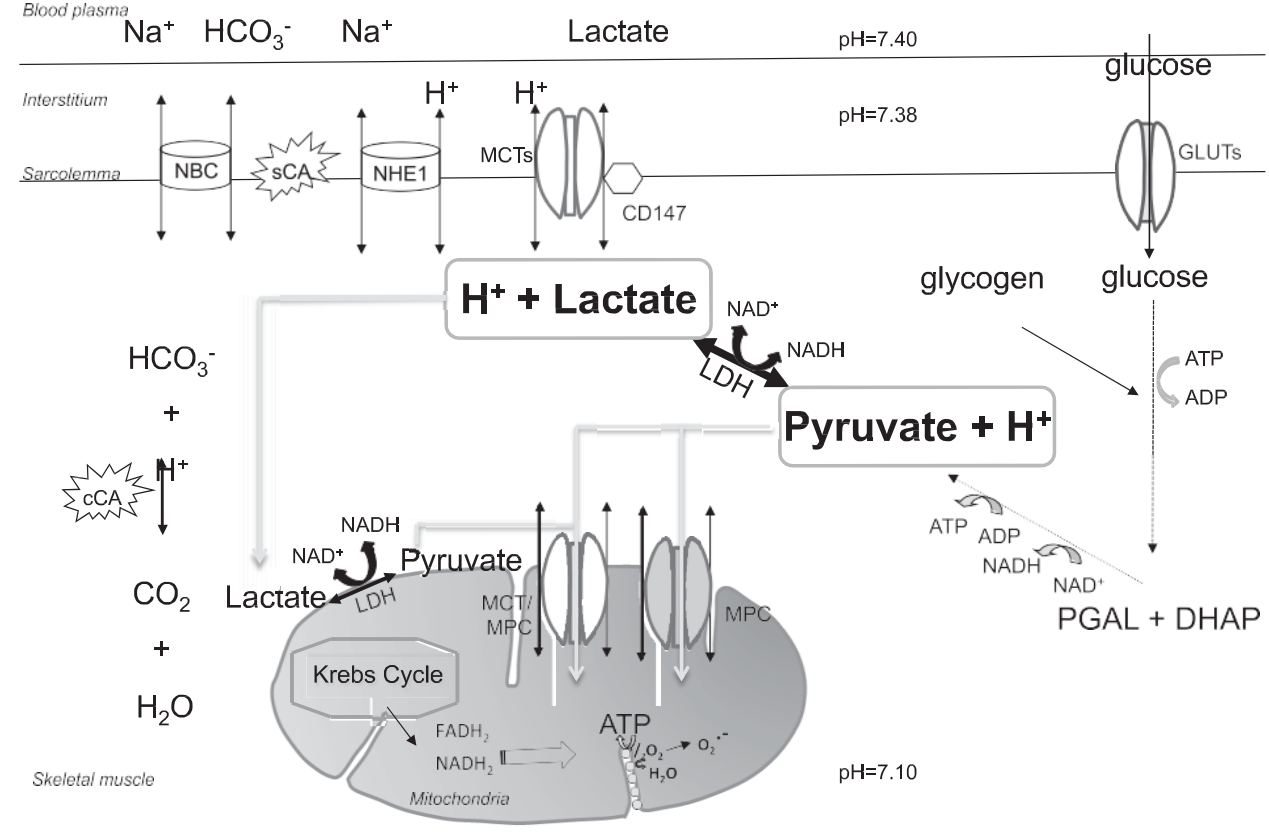

Fig. 1. Presentation of muscle lactate and proton regulation. Carbonic anhydrase (CA) exists as cytosolic (cCA) and membranebound (sCA) CA isoforms. NBC, sodiumbicarbonate cotransporter; NHE1, $\mathrm{Na}^{+}-\mathrm{H}^{+}$ exchanger isoform 1; MCTs, monocarboxylate transporters (lactate-proton co-transporter); GLUTs, glucose transporters; CD147, cluster of differentiation 147; PGAL, phosphoglyceraldehyde; DHAP, dihydroxyacetonephosphate; LDH, lactate dehydrogenase; MPC, mitochondrial pyruvate carrier. $\mathrm{pH}$ values in blood plasma, interstitium, and skeletal muscle are values at rest.

In working muscle, MCTs have a role in facilitating $\mathrm{H}^{+}$effl and thus preventing major decrements in intracellular $\mathrm{pH}$ during vigorous exertion $(68,71,72)$. For example, a decrease in intracellular $\mathrm{pH}$ of 0.5 units accelerates the lactate $/ \mathrm{H}^{+} \mathrm{fl}$ rate by $=50 \%$. The subsequent increase in lactate and proton efflux from working myocytes reduces lactate accumulation and limits the decline of intracellular $\mathrm{pH}$. The proton-coupled lactate efflux from Type II fibers, and concomitant decrease in both interstitium and plasma $\mathrm{pH}$, will promote lactate (and proton) uptake by adjacent Type 1 muscle fibers (71). Therefore, the direction of this cotransport appears to be a function of the $\mathrm{pH}$ and lactate gradients, as lactate transport capacity in giant vesicles has been demonstrated to be identical in both directions (73).

Other proteins expressed in the sarcolemmal membrane, such as the carbonic anhydrase enzyme (CA) (52), and the sodium-bicarbonate cotransporter (NBC) (5), also influence extracellular $\mathrm{H}^{+}$exchange and concentration (Fig. 1) and, therefore, complement the actions of the MCT isoforms $(5,7$, 8). For example, $\mathrm{CA}$ helps to establish a fast equilibria between carbonic acid and $\mathrm{CO}_{2}, \mathrm{HCO}_{3}$, and $\mathrm{H}^{+}(52)$. The activity of $\mathrm{CA}$ in muscle is mediated by different isoenzymes, which are located in the extracellular sarcolemmal [sCA isoform, CAIV (52)], or cytosolic [cCA isoform, CAII $(52,79)]$ compartment. Extracellular sCA facilitates lactate/proton transport across the sarcolemma by acting as an interstitial proton acceptor, and, therefore, maintaining the $\mathrm{pH}$ gradient $(52,149)$. Furthermore, sCA has been shown to facilitate lactate/proton exchange in rat skeletal muscles (149), and when MCT1 and cCA are coexpressed in oocytes, they cooperate with a binding of CA to the MCT1 in the cell membrane of the oocyte that greatly enhances the $\mathrm{H}^{+}$flux via the MCT1 (7); it should be noted, however, that the effect of carbonic anhydrase on MCT1 is independent of its catalytic activity. Similar results have recently been observed between MCT4 and cCA (8). In humans, inhibition of extracellular and intracellular $\mathrm{CA}$ has been demonstrated to be associated with a lower plasma lactate concentration during incremental exercise (135), presumably due to less lactate efflux via MCT.

Different isoforms of NBC have also been detected and quantified in human $(79,82)$ and rat $(82,143)$ skeletal muscles. Furthermore, we have reported a significant correlation between NBC and MCT1 relative abundance $(r=0.50, P<$ 0.01 ) in oxidative, but not glycolytic, rat muscle (143). For example, in rats an increase in bicarbonate concentration of the outer medium increased the activity of the NBC (82). As a consequence, it may be that the regulation of muscle $\mathrm{pH}$ via NBC may promote MCT transport activity during high-intensity exercise. Indeed, when MCT1 is coexpressed in frog oocytes with isoform one of NBC (NBC1), lactate transport influx in this isolated system is enhanced (5) as a result of the increased proton buffer capacity in the presence of NBC1 expression, i.e., once again by maintaining the $\mathrm{pH}$ gradient. Further research is required to determine whether there is a colocalization and coupling in activity of the different isoforms of NBC with MCT1 and MCT4 in human skeletal muscle.

Full NBC activity has been reported to depend on the cooperation of $\mathrm{sCA}(79)$ and $\mathrm{cCA}(1,6,52)$. Therefore, although the colocalization of MCT1, NBC, and CA has not yet been demonstrated in skeletal muscle, we can hypothesize that the cooperation of these proteins may be of physiological importance for lactate/proton exchange during high-intensity exercise. These interactions could act to suppress the buildup of intracellular $\mathrm{H}^{+}$and to maintain the $\mathrm{pH}$ gradient that is required for continued MCT activity (75). Future studies should verify these hypotheses for lactate influx and efflux in mammalian muscles. Future research should also determine whether there is a coexpression of these proteins in the sarcolemmal membrane and to evaluate the lactate/proton transport capacity in human sarcolemmal vesicles, as currently performed (78), with and without the presence of inhibitors of NBC and CAs activity. 
Implications for performance. A high muscle lactate/proton transport capacity may help to limit the accumulation of lactate and protons in the cytosolic compartment. This could counteract the negative consequences of cellular acidification, which has been proposed to contribute to the appearance of muscle fatigue (140). Despite contrasting views in the literature (87, $112,114)$, it has been demonstrated that both protons (133) and lactate (63) may contribute to the appearance of muscle fatigue during muscle contractile activity. Indeed, an improved ability to extrude $\mathrm{H}^{+}$from the muscle will reduce the decrease in muscle $\mathrm{pH}$ for a given lactate production, which may delay the development of fatigue $(103,115,144)$. Similarly, the accumulation of lactate ion per se within skeletal muscle may affect excitation-contraction coupling and, consequently, reduces muscle force independent of any $\mathrm{pH}$ changes; this suggests another mechanism by which a higher lactate transport capacity can delay fatigue appearance $(63,83,139)$. These notions are supported by the observation of a low, but significant relationship between lactate transport capacity and the fatigue index $(r=0.33 ; P<0.05)$ measured during $50 \mathrm{~s}$ of onelegged, maximal, knee-extensor exercise (115). Similarly, Thomas et al. (144) have reported that fatigue indices measured during continuous, 1-min, all-out and intermittent (repeated 10-s cycling sprints interspersed with $30 \mathrm{~s}$ of recovery) supramaximal exercise, were inversely related to MCT1 content $(r=0.54, P<0.05$ and $r=0.58, P<0.05$, respectively), but not MCT4 content, in 15 humans with different training status. Nevertheless, this result is in contrast to that obtained for lower-intensity exercise, since both MCT1 and MCT4 content in a homogeneous group of trained athletes was not correlated with performance when subjects were required to cycle at the highest sustainable power output for 2 and $10 \mathrm{~min}$ (9). As limited data are available in humans regarding MCT content and exercise performance, further research is required to investigate the effects of the population studied (homogeneous or heterogeneous, trained or untrained) and exercise intensity on the relationship between MCT content and exercise performance.

\section{Regulation of MCT Content with Acute Exercise}

There is a paucity of research on the effects of acute exercise on muscle membrane lactate transporter content. It is known that increased transmembrane lactate flux during exercise results from both increased transmembrane lactate and proton gradients $(20,68)$, in cooperation with regulatory proteins $(5$, $7,8)$; an increased intrinsic activity of the transporters, measured in giant vesicles, has also been observed in one study (72). However, how lactate transport is altered as a function of exercise intensity, during and immediately after exercise, is not clear, and the effects of an acute exercise bout on human skeletal muscle lactate transporter content have only been investigated in a few experiments.

Effects of acute exercise on MCT content. Despite limited research, it appears that both MCT1 and MCT4 belong to a class of proteins that can be rapidly affected by an acute bout of exercise. Prolonged low-intensity exercise has been reported to acutely increase MCT content in both humans (55) and rats (35), with increases in MCT1 and MCT4 observed 2-6 days after a 5- to 6-h cycle training session at $60 \%$ of $\mathrm{VO}_{2}$ max in untrained humans (55). During $16 \mathrm{~h}$ of heavy, intermittent, cycle exercise (6 min of exercise at $90 \%$ of $\dot{\mathrm{V}}_{\mathrm{O}_{2} \text { max }}$ per $\mathrm{h}$ for $16 \mathrm{~h}$ ) in untrained subjects, a rapid increase of MCT4 content has been reported (24\%), with no change in MCT1 (56). Surprisingly, the opposite results (no change in MCT4 and increase of MCT1) were observed in moderately trained endurance runners $2 \mathrm{~h}$ after a time-to-fatigue test performed at $110 \%$ of $\mathrm{vV}_{\mathrm{O}_{2} \max }$ (the minimal velocity to elicit $\mathrm{VO}_{2}$ max ) (14). Recently, Bishop et al. (18) have observed a significant decrease in both MCT1 ( $24 \%$ ) and MCT4 ( 26\%) content in total membrane preparations immediately after very exhaustive exercise (45 s at $200 \%$ of $\mathrm{VO}_{2} \max$ ) in six active women. This is in line with the results of Tonouchi et al. (145), who reported a decrease in the plasma membrane content of both MCT1 ( $10 \%$ ) and MCT4 ( 25\%) immediately following $10 \mathrm{~min}$ of high-intensity electrical stimulation in rats. Because of the limited number of studies, it is difficult to reconcile these contrasting findings. However, they may be the result of several factors, such as the type of exercise (duration, intensity, continuous vs. intermittent) and the type of subjects (trained vs. untrained, male vs. female). Alternatively, taken together, these contrasting findings may also be due to the timing of the muscle biopsy samples.

If we focus on the time course of the protein content measured after the start of exercise, rather than once exercise ended (Fig. 2), one can observe a rapid decrease in membrane MCT1 and MCT4 content ( $>20$ to $25 \%$ ) between $45 \mathrm{~s} \mathrm{(18)} \mathrm{and}$ $10 \mathrm{~min}$ (145), no change from $30 \mathrm{~min}$ to $1 \mathrm{~h} 20 \mathrm{~min}(45,46)$, and an increase in MCT1 content $(+50-60 \%) 2 \mathrm{~h}$ after the beginning of exercise $(14,35)$. MCT1 content has been reported to remain elevated 7,12 , and $26 \mathrm{~h}$ after the onset of exercise in the red (RG) and white (WG) gastrocnemius, and in the soleus (Sol) of rats (35). Whereas no change was reported for human MCT4 content $2 \mathrm{~h}$ after the onset of a time-tofatigue test at $110 \%$ of $\mathrm{vV}_{\mathrm{O}_{2} \text { max }}$, increases in MCT4 content have been observed in the RG and Sol $2 \mathrm{~h}$ after the onset of exercise in rats, with a peak occurring after $12 \mathrm{~h}$ (35); MCT4 protein was also still upregulated after $26 \mathrm{~h} \mathrm{(35).} \mathrm{Thus,} \mathrm{it}$ appears that 5-24 $\mathrm{h}$ after the start of exercise, there is an increase in membrane MCT content, after a previous and brief

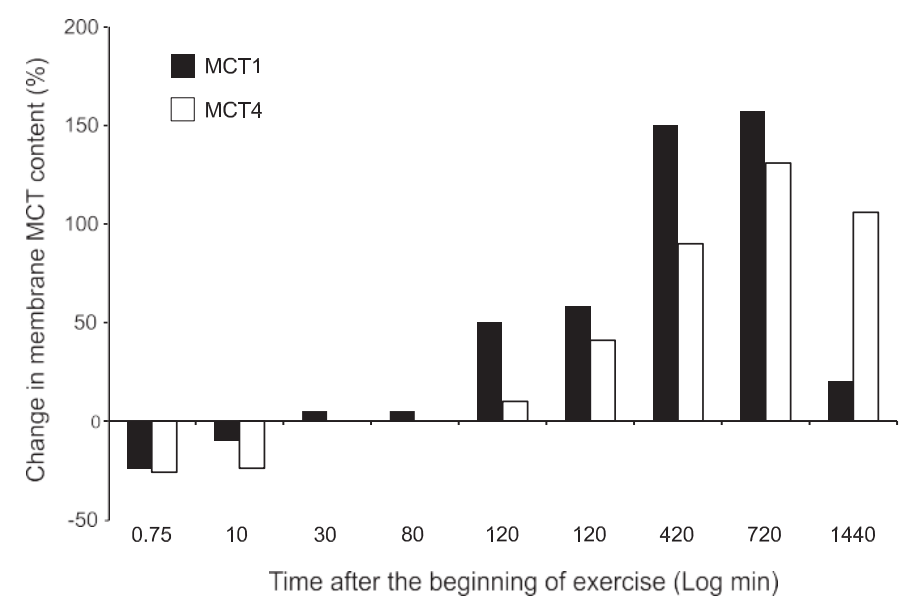

Fig. 2. The kinetics of MCT content measured during the recovery from exercise, but taking into account the time from the beginning of exercise to when the biopsy was performed. [Data in figure from studies of Bishop et al. (18), Tonouchi et al. (145), Eydoux et al. (45, 46), Bickham et al. (14), and Coles et al. (35).]. 
decrease in membrane protein content. This proposed time course for the response of MCT to acute exercise needs to be confirmed, as it is based on a small number of studies performed with different types of exercises and different populations. Further study is also required to determine whether the decrease in MCT content immediately after exercise results from the intensity of exercise and/or the short exercise time until the collection of the biopsy and whether this decrease could be an acute response to exercise by which training leads to chronic increases in muscle MCT content. These findings also have important implications for the design of training studies, e.g., it may be important for researchers to avoid training in the $24-48 \mathrm{~h}$ before the biopsy to try and ensure that any observed changes are not due to the acute effects of the last training session.

Potential mechanisms involved in the reported changes in MCT content with acute exercise. The decrease in MCT1 and MCT4 content after high-intensity exercise may be expected to decrease rates of lactate and proton removal from the cell. Consistent with this, a decrease in sarcolemmal lactate transport capacity has been observed after time to fatigue exercise in both untrained $[72 \pm 19 \min (40)$ and $80 \pm 9 \min (46)]$ and trained [204 \pm 11 min (46)] rats. However, a decrease in lactate transport capacity has also been observed after $30 \mathrm{~min}$ of submaximal exercise (45), without changes in MCT1 content $(45,46)$. Although the physiological significance of these findings is unclear, these alterations are also in agreement with the slower blood lactate appearance ()$I_{1}$ ) and removal ()$\left.I_{2}\right)$ rate constants observed immediately following high-intensity exercise in humans $(48,113)$. These studies reveal the complexity of the effects of acute exercise on the exchange of lactate measured during recovery.

The reported decrease in membrane MCT content following an acute bout of exercise $(18,145)$ could be due to a number of factors that require further investigation, including lipid peroxidation, which may also lead to fluidity and permeability alterations in the membrane $(36,137)$, intracellular translocation, and protein carbonylation (4). One could hypothesize that protein carbonylation could affect the conformation of proteins inside the sarcolemmal membranes, due to changes in its interaction with residues, with consequences for the intrinsic activity of the transporter and/or the recognition by the antiMCT1 or anti-MCT4 antibody using Western blot analysis. Alternatively, Tonouchi et al. (145), hypothesized that the decrease in MCT4 and MCT1 content that they observed after acute muscle contractions may have been due to translocation of the protein to an intracellular pool. Intracellular pools of MCT1 have been observed in cardiac myocytes during postischemic hypertrophy, which was associated with up-regulation of MCT1 (65). However, this phenomenon needs to be confirmed in skeletal muscle in response to acute exercise.

Concomitantly with the above described changes, it is likely that there is an increase in MCT protein synthesis. This would explain the time course illustrated in Fig. 2, whereby there is an initial decrease in MCT content, followed by no change and then a significant increase. Potential mechanisms controlling this increase in protein synthesis are described in Which Cellular and Molecular Signals/Mechanism Regulate Muscle MCT Content? Furthermore, on the basis of results of the few studies that have reported changes in both MCT mRNA and protein at different times postexercise, it can be concluded that exercise-induced regulation of MCT protein expression is complex, since there is not a simple concordance between the rate of gene transcription, mRNA expression, and changes in protein levels after $2 \times 5$ min of intense muscle contractions induced by electrical stimulation (145) or following $2 \mathrm{~h}$ of exercise (35) in rat muscles. The results of studies on laboratory animals are, however, consistent with those of a human study that demonstrated an increase in MCT1 protein level, without any changes in mRNA content, $2 \mathrm{~h}$ following a bout of high-intensity exercise (time-limit test at $110 \%$ of $\mathrm{v}_{\mathrm{V}_{2} \text { max }}$ ) (14). This suggests that MCT expression may be regulated primarily by posttranscriptional mechanisms, or by a combination of posttranscriptional regulation and pretranslational mechanisms $(14,23,24)$, at least in skeletal muscle (23). Further studies are needed to clarify the role of transcriptional regulation on the acute expression of these proteins in response to exercise.

\section{Regulation of MCT with Chronic Exercise}

Changes in MCT1 and MCT4 content as a function of training status. When subjects with different training status are studied, well-trained endurance subjects present significantly higher MCT1 content $(P<0.05)$, compared with less-trained subjects, with a trend also for higher MCT4 content $(P=0.10)$ (144). Similarly, lactate transport activity measured in human skeletal muscle is significantly higher $\left(>75 \mathrm{pmol} \cdot \mathrm{cm}^{2} \cdot \mathrm{s}^{1}\right)$ in well-trained endurance athletes $\left(\dot{\mathrm{V}}_{2 \max }=70 \mathrm{ml} \cdot \mathrm{min}^{1} \cdot \mathrm{kg}^{1}\right)$ compared with sedentary $\left(\dot{\mathrm{V}}_{2}\right.$ max $\left.=48 \mathrm{ml} \cdot \mathrm{min}^{1} \cdot \mathrm{kg}^{1}\right)$ and moderately trained subjects $\left(\dot{\mathrm{VO}}_{2 \max }=62 \mathrm{ml} \cdot \mathrm{min}^{1} \cdot \mathrm{kg}^{1}\right)$, who both presented a lactate transport capacity of 57 $\mathrm{pmol} \cdot \mathrm{cm}^{2} \cdot \mathrm{s}^{1}(115)$. It is interesting to note that the highest lactate transport capacities were observed in two track cyclists $\left(>100 \mathrm{pmol} \cdot \mathrm{cm}^{2} \cdot \mathrm{s}^{1}\right)$, who competed in the $4-\mathrm{km}$ pursuit (one obtained a bronze medal at the 1992 Olympic Games) and who combined training on the road with high-intensity track training $\left(\dot{\mathrm{V}}_{2} \max >78 \mathrm{ml} \cdot \mathrm{min}^{1} \cdot \mathrm{kg}^{1}\right)$. The results of these two cross-sectional studies support the hypothesis that contractile activity is an important stimulus to increase MCT content.

Longitudinal studies. Few training studies have not observed an increase in either MCT1 $(3,17,44)$ or MCT4 $(17,44,108)$ content. For example, increases in MCT have been reported after endurance $(21,39,44)$, strength $(76)$, all-out sprint (14, $31,108,116)$, and interval training $(17,77)$. In contrast, $1 \mathrm{wk}$ of detraining, after training in humans, leads to a lower MCT1 and MCT4 content (31). This is in agreement with the lower lactate transport capacity observed after extreme inactivity in laboratory animals (41, 96, 117). For example, significant decreases in lactate transport activity have been observed in sarcolemmal vesicles isolated from the hind limb skeletal muscles of tail-suspended rats (41) and from denervated rat skeletal muscle $(96,117)$. Thus, consistent with the observations from cross-sectional studies, the results from these longitudinal studies support the hypothesis that contractile activity is an important factor regulating the lactate transport system. Furthermore, analysis of the mean data from the 10 human training studies available in the literature suggests that the percentage increase in MCT1 and MCT4 content in response to contractile activity is related $(r=0.81, P<0.01$; Fig. 3$)$. However, changes in MCT1 content following training are approximately twice those of MCT4, which suggest that MCT1 


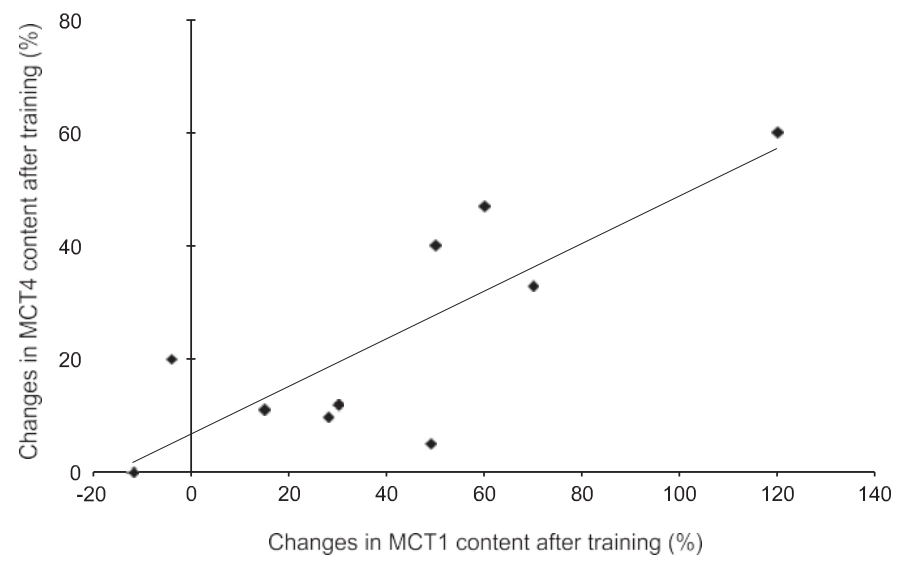

Fig. 3. Relationship between percentage changes in human MCT4 and MCT1 content $(r=0.81, y=0.42 x+6.7, P<0.01)$ from mean data of 10 studies available in the literature $(14,17,21,31,39,44,76,77,108,116)$.

protein expression is more sensitive to training than MCT4 protein expression.

Initial fitness of subjects. As summarized in Table 1, changes in MCT1 and MCT4 content with chronic contractile activity do not appear to be strongly infl by the initial level of training since both sedentary $(21,39,76,77)$, active $(108,116)$, and moderately trained $(14,17,31)$ subjects respond to increases in physical activity level by augmenting muscle MCT content. However, the results of one of the few studies conducted with elite athletes suggest that daily training at a high intensity may be required to maintain, but not enhance, MCT protein content (44). In that study, moderate-intensity training (following a period of intensive training during the racing season) led to a decrease in MCT content in these elite, endurance-trained subjects (elite junior cross-country skiers with high $\dot{\mathrm{V}}_{2}$ max values [73 and 58 $\mathrm{ml} \cdot \mathrm{min}^{1} \cdot \mathrm{kg}^{1}$ in men and women, respectively)]. In consequence, one can speculate that training above a certain intensity may be required to increase MCT content in elite athletes, but no further increase in MCT content appears after weeks or months of daily training at this intensity (44). In contrast, in less-trained subjects increases in chronic contractile activity may induce increases in MCT content without a strong effect of the initial fi of subjects.

Training characteristics (intensity, duration, volume). An important question is how much and what kind of training is required to maximally increase MCT content? Training factors that could infl training-induced changes in MCT content, such as the type of training, the intensity and duration of individual training sessions, and the duration and total work of the training period, are now investigated to highlight the various factors that may be involved in the regulation of MCT content.

As reported in Table 1, all types of training (endurance, speed endurance training, repeated-sprint training, and strength training) have been reported to increase MCT1 and MCT4 content, with a large variation in the response. For example, endurance training has been reported to increase MCT1 content

Table 1. A summary of the characteristics and results of training studies that have investigated changes in MCT content in humans

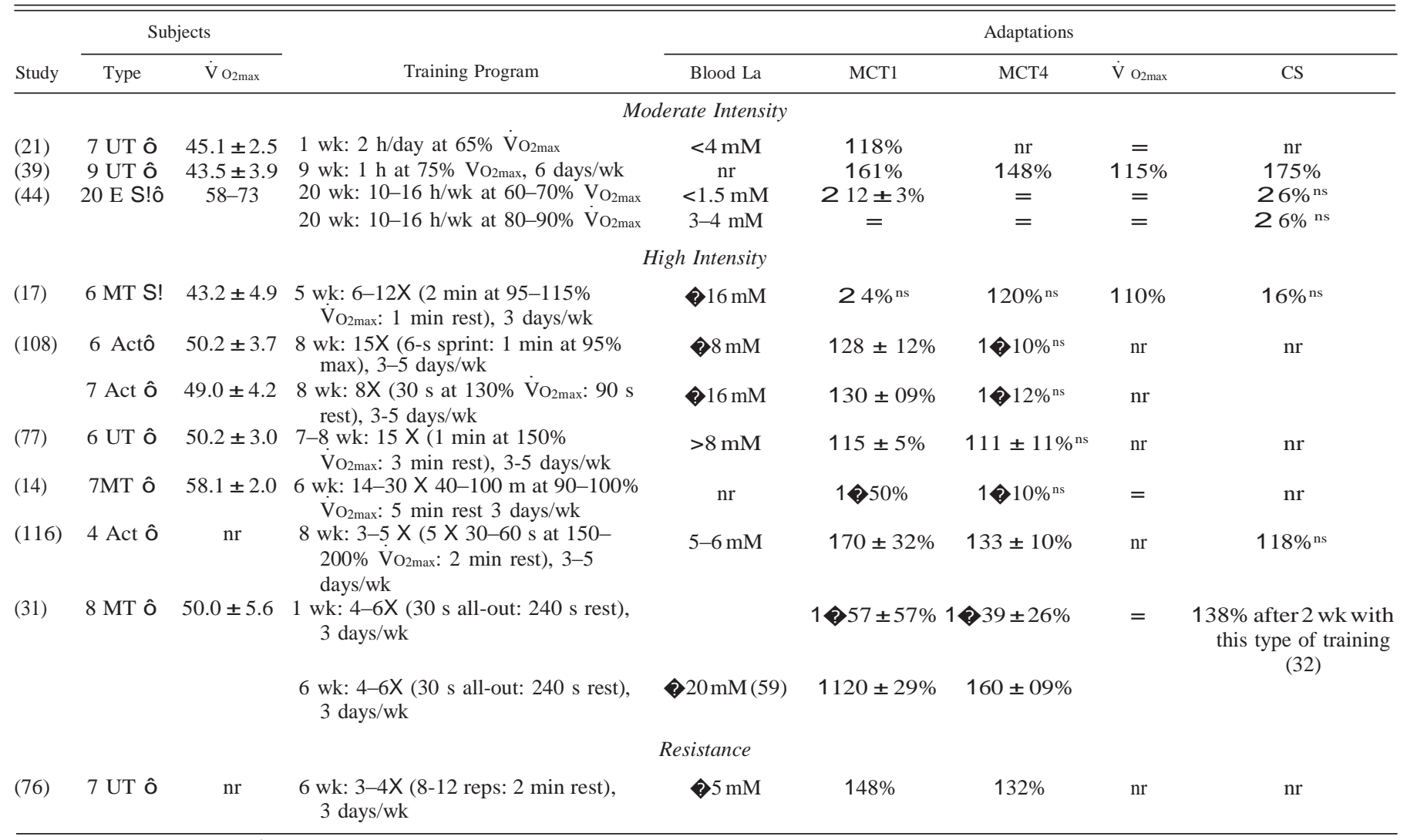

Results are means \pm SE. $\dot{V}_{2 m a x}=\mathrm{ml} 1 \cdot \mathrm{kg}^{1} 1 \mathrm{~m}{ }^{1} ;$ MCT, monocarboxylate transporters; La, lactate; CS, citrate synthase; UT, untrained; Act, active; MT, moderately trained; E, elite; ô, males; S!, females; nr, not reported; =, no change; ns, not significant. 
by $18 \%$ [with a range of 0 to $62 \%$ in this study (21)] to $61 \%$ (39), and has also been reported to induce large interindividual variations (with increases or decreases in individual subjects) in MCT4 content (39). MCT1 and MCT4 content has been reported to increase by $15 \%$ (77) to $120 \%$ (31) and by 0 (108) to $60 \%(31)$, respectively, in response to high-intensity training, except for two human studies where no significant changes were observed for either protein $(17,44)$.

It has previously been suggested that the intensity of contractile activity during training is not of importance for the increase in skeletal muscle MCT1 content, whereas increases in MCT4 content seem to depend on a high intensity of contractile activity (76). However, if we focus on the program variables for the eight high-intensity training protocols, the increase in both MCT1 and MCT4 content is related to the intensity of the individual training sessions $(r=0.59$ and $r=$ 0.71 , respectively, $P<0.05$ ) (data from eight training protocols used in six studies in Table 1). Thus, the research to date suggests that the training intensity appears to be an important variable influencing changes in MCT content. As these conclusions are based on correlations using mean data, they need to be confirmed, especially as few protocols (only 8 in humans) have focused on high-intensity training-induced changes in both MCT1 and MCT4 content. In addition, we must be cautious in this interpretation since, at high intensity, two types of training induced similar changes in MCT1 and MCT4 content (108). Furthermore, it is very difficult to interpret the results of the small number of studies published to date due to differences in the initial fitness of subjects and the timing of the post-training biopsy (discussed below).

The duration of individual training sessions does not appear to be of importance for increasing muscle MCT protein expression. No correlations were found between the percentage increase in MCT1 and MCT4 content with training and the duration of the individual training sessions (Table 1). This suggests that a long-duration training session is not necessary to induce increases in MCT content. Instead, as discussed in the previous paragraph, the metabolic perturbations induced by short and high-intensity contractile activity appear to be more effective to stimulate increases in MCT content. Similarly, lactate transport capacity in humans appears unaffected by physical activity within a broad range of fitness levels (from sedentary to well trained). The finding that no subject with a $\dot{\mathrm{V}}_{\mathrm{O}_{2} \text { max }}<68 \mathrm{ml}{ }^{1} \cdot \mathrm{kg}^{1} \cdot \mathrm{min}^{1}$ had an elevated lactate-transport capacity indicates that a high volume of training, including frequent bouts of high-intensity exercise, is likely to be necessary to improve the lactate transport system (115). These results are confirmed by results of experiments on laboratory animals because, in rats, improved lactate transport capacity is detectable only in some muscles after high-intensity exercise training and only when measured with giant sarcolemmal vesicles $(80,118)$. In contrast, no change in lactate transport was observed with small sarcolemmal vesicles (131), which could be inherent in the vesicle model used in these studies, since small sarcolemmal vesicles are constituted with predominantly glycolytic hind limb muscles. Further research is clearly required to determine the optimal intensity and duration of a training session to promote improvements in both MCT content and lactate transport capacity.

It is a common observation that many adaptations to training are related to the duration of training and to the total work performed during training. One could, therefore, hypothesize that the duration and/or the total work (number of repetitions $X$ exercise duration $\mathrm{X}$ exercise intensity expressed as a percent of $\dot{\mathrm{V}}_{2 \text { max }}$ ) performed during the training period may affect the changes in skeletal muscle MCT1 and MCT4 content. To date, the duration of the training period used in studies has ranged from $1 \mathrm{wk}$ (31) to $9 \mathrm{wk}$ (39). However, analysis of the moderate- and high-intensity studies in the literature (Table 1) does not indicate any relationship between the duration or the total work of the training period and increases in MCT1 or MCT4 content $(P>0.05)$. The maximal response to training appears to be quickly reached as Juel et al. (77) observed no further increase in MCT content between 4 and 7-8 wk of training, and years of training, as performed by athletes, does not seem to produce further increases (44). Thus, total time of exercise appears to be less important than the intensity of exercise training for increasing MCT content.

Influence of the timing of the post-training biopsy. Part of the inconsistent response of MCT to training may be attributable to the timing of the post-training biopsy. For example, Fig. 2 (see Sarcolemmal Lactate/Proton Cotransporters in Skeletal Muscle) would suggest that the smallest changes in MCT content are likely to be observed when the posttraining biopsy is performed close to the last training session. Consistent with this observation, the lowest increase in MCT content is observed when biopsies are performed immediately at the end of the last training session (108) or following the posttraining test (77). Percentage changes in MCT1 and MCT4 content, compared with pretraining, progressively increase with a greater delay of the posttraining biopsy, i.e., from $24 \mathrm{~h}(21,76)$, to 48 $\mathrm{h}(14,39,116)$ after the last training session, with the highest gain observed when the biopsy is performed $72 \mathrm{~h}$ after the last training session (31). This observation is consistent with the known time course for increase in protein synthesis, but also with studies reporting tapering to elicit greater physiological adaptations due to a supercompensation following a reduction in training before competition (110). Other physiological

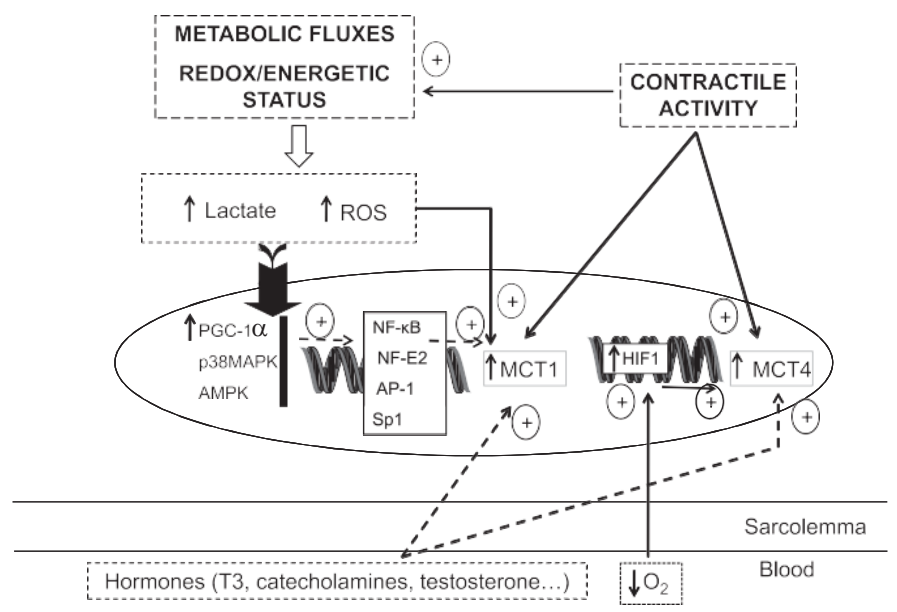

Fig. 4. Molecular and cellular factors known and suspected to affect MCT content and activity. Solid arrows denote factors known; dashed arrows denote factors suspected; + denotes stimulation. T3, thyroid hormone; ROS, reactive oxygen species; PGC-1a, peroxisome proliferator-activated receptor-)l coactivator; p38MAPK, p38 mitogen-activated protein kinases; AMPK, 5= adenosine monophosphate-activated protein kinase; NF-KB, nuclear factor-KB; NF-E2, nuclear factor-erythroid-derived 2; AP-1, activated protein-a; Sp1, stimulating protein-1; HIF1, hypoxia-inducible factor 1. 
changes during taper, such as an increase in citrate synthase activity and glycogen concentration, have also been reported $(111,138)$. Further studies are needed to confirm this potential kinetics of protein expression after low- and high-intensity training, and to test the effects of tapering on MCT1 and MCT4 content and lactate transport capacity. Indeed, to our knowledge, no studies have taken into account the importance of a taper after training, or the timing of the posttraining biopsies, when analyzing changes in MCT content following training.

\section{Which Cellular and Molecular Signals/Mechanisms Regulate Muscle MCT Content?}

The regulation of skeletal muscle MCT1 and MCT4 content by a variety of stimuli has been demonstrated, and evidence has been presented for both transcriptional and posttranscriptional regulation $(24,35,43,58,75,148)$. At present, the question is which signal(s) is(are) behind the training-induced changes in MCT1 and MCT4 content? However, because of the limited number of studies available to answer this question, we have chosen to summarize the potential role of intracellular factors (such as lactate), and other factors, which may alter muscle metabolism (such as hormonal factors, hypoxia, nutrition, and metabolic disturbances). We also specifically comment on cellular states that produce an increase in muscle and blood lactate concentration to help understand factors, which may regulate MCT content with exercise (Fig. 4).

Products of muscle glycolytic activity during exercise. Lactate is continuously produced even under fully aerobic conditions (28), especially during exercise when rates of glycogenolysis and glycolysis are elevated (29). As a consequence, high lactate concentrations could be involved in triggering adaptations in lactate/proton transport in response to high-intensity training. However, if we focus on the peak blood lactate concentration measured (or estimated) during training (Table 1 ), and the percentage increase in MCT content, no correlations were found in these longitudinal studies. Furthermore, Mohr et al. (108) have reported no significant differences in MCT1 and MCT4 content following two training programs that elicited very different blood lactate values (blood lactate concentrations of $\geqslant 8$ and $16 \mathrm{mM}$ ). These observations are consistent with the fi that chronic, low-frequency stimulation of the rat tibialis muscle for 7 days produced a doubling of the lactate transport capacity despite minor increases in plasma lactate (97).

However, blood lactate levels can be low even though turnover in the blood and muscle lactate concentration are relatively high (13). In accordance with this statement, no relationship was reported between muscle and blood lactate concentration when subjects performed repeated intense exercise $(33,84,85)$. In contrast, following continuous exercise, where the blood lactate concentrations are low, the muscle lactate concentrations are closely related to values observed in the blood $(85,86)$. Thus, we cannot conclude from the 10 studies published to date that there is evidence to support the local formation of lactate, during the training bouts, as an important factor stimulating increases in lactate/proton transport capacity. Equally, we cannot exclude the possible role of repeated increases in lactate concentration during high-intensity training session to stimulate both MCT expression and lactate transport activity $(3,77,115,116)$. This suggests that factors associated with physical activity are also involved in the lactate transport rate increase when lactate concentration is low during training.

Other factors than muscle glycolytic activity during exercise potentially affecting muscle MCT regulation. Alteration of MCT content in response to exercise is not solely due to muscle contractile activity, even if this factor is the most studied and well known, but may also be attributable to other stressors such as hormonal factors, hypoxia, caloric restriction, altered metabolism, or factors related to muscle contractility, such as calcineurin pathway. These factors can act through specific pathways, certainly interconnected, to modify gene expression and induce muscle adaptations to training. Indeed, one thing that muscle contractile activity, oxygen tension, and insulin resistance have in common is an increase in muscle and blood lactate concentration, which has led to the suggestion that lactate may play a role in regulating MCT content.

Discrepancies exist concerning the hormonal regulation of MCT content, and each protein isoform seems to respond differently to hormonal stimulation, also at the posttranscriptional level. Following 7 days of thyroid hormone (T3) ingestion, rat sarcolemmal MCT4, but not MCT1, content increased, whereas mRNA expression of both transporters was increased (148). In this experimental protocol, rats were kept in a cage and did not perform exercise. In addition, testosterone administration in rats induces increases in both sarcolemmal lactate transport capacity and MCT1 and MCT4 protein content, but without affecting mRNA expression (43). These last results may help to explain the absence of training-induced changes in MCT content (17), and lactate-transport capacity (131), after high-intensity training in untrained women and in female rats, respectively. Despite limited research, sex has been reported to exert a strong influence on gene expression (132). Direct measurement of changes in MCT relative abundance in males and females, exposed to the same training stimulus, is required to test the hypothesis that sex hormones influence traininginduced changes in MCT proteins. Nonetheless, different types of training may be required to alter MCT content in males and females.

Against the hypothesis that humoral factors during exercise may play an important role in regulating MCT content, Juel et al. (76) observed different changes in MCT content in trained and untrained legs with a one-legged training protocol. On the basis of these observations, they proposed that humoral, bloodborne factors can be excluded and that changes in MCT1 content must depend upon local, contraction-induced factors.

A decrease in muscle oxygen tension, due to exercise at altitude or due to alteration in $\mathrm{O}_{2}$ diffusion, has been proposed to stimulate gene expression leading to muscle oxidative adaptations $(2,136)$. To date, however, the only published human study (79) has reported no changes in MCT1 and MCT4 content in European lowlanders after 2 and $8 \mathrm{wk}$ at altitude (4,100 m, Bolivia), compared with muscle biopsy samples obtained at sea level. However, the authors did observe changes in sarcolemmal CA density, which may improve lactate and proton transport across the sarcolemma by regulating the $\mathrm{pH}$ gradient (see Cellular regulation: role of the $\mathrm{pH}$ gradient in regulating lactate transport activity during exercise?). To date, studies on laboratory animals have produced contrasting results regarding changes in MCT content in response to chronic hypoxia. Juel and Pilegaard (80) reported 
that lactate transport capacities in both red and white rat muscles were unchanged after chronic hypoxic treatments, whereas McClelland and Brooks (94) observed a tissue-specific increase of MCT1 and MCT4 content in the skeletal muscles of rats exposed to a chronic high altitude of $4,300 \mathrm{~m}$. In addition, Py et al. (124) observed an increase in lactate transport capacity following chronic exposure to $5,500 \mathrm{~m}$, with an increase in MCT4, but not MCT1, in oxidative muscles only. In agreement with Py et al. (124), Ullah et al. (147) have reported that hypoxia increased the in vitro expression of MCT4 mRNA and protein, but not MCT1, through a hypoxiainducible factor 1a-mediated mechanism. Differences between these animal studies remain unexplained, but could be related to a sex hormone effect, the use of females (94) compared with males $(80,124)$, or to differences in type and duration of the altitude exposure [20 $\mathrm{min}$ a day 5 days/wk for $3 \mathrm{wk}(80), 21$ consecutive days (124), $8 \mathrm{wk}$ (94)]. It is noteworthy that the only study presenting no increase in MCT content was also the study that contained the smallest exposure to altitude (80). Although the lowered oxygen tensions is the most likely factor explaining increases in MCT following long-term exposure of rat to hypoxia, it also needs to be considered that hypoxia is associated with a decrease in food consumption, compared with normoxic rats (15), and that caloric restriction may independently affect MCT content (see below).

The effects of caloric restriction have been highlighted by the results of Py et al. (124), since most of the effects of chronic hypobaric hypoxia on increases in lactate transport were mediated by the associated anorexia. This was demonstrated by the use of pair-fed rats that were exposed to normoxia and pair-fed quantities of food equivalent to those consumed by animals subjected to hypoxia. In agreement with this result, caloric restriction (88) or a high-sucrose diet (Lambert K, Thomas C, Metz L, Py G, Mercier J., unpublished data), increases sarcolemmal lactate transport capacity, compared with a control diet. Since expression of the transporters was unchanged after caloric restriction (80), lactate exchange improvement may have resulted from an increase in translocation inside the membrane, an increased affinity for lactate and/or conversion to another MCT isoform, such as MCT2 (which has also been detected in muscle). These results emphasize the importance of controlling and recording nutritional intake in studies seeking to investigate the effects of an exercise intervention on lactate transport or MCT content.

Another factor that may modify the effects of exercise training on MCT content is the existence of metabolic pathologies, such as diabetes, where both carbohydrate and lipid (the major substrate during submaximal exercise) metabolism is modified. In these situations of metabolic disturbances, rats with streptozotocin (STZ)-induced diabetes, present elevated resting blood lactate compared with healthy rats $(42,126)$. In contrast, obese insulin-resistant Zucker fa/fa rats do not present a systematic elevation in resting plasma lactate $(105,127)$; nonetheless, a reduction in lactate uptake has also been observed on sarcolemmal vesicles in these animals (105). The effects of training on MCT content in diabetic states have only been investigated in a few studies. Strength training in type 2 diabetic human subjects increased (76) and normalized MCT1 content. After endurance training, Zucker $f a / f a$ rats showed an increase in both lactate uptake and sarcolemmal MCT1 expression (105). The type and intensity of training do not seem of importance to normalize MCT1 content in type 2 diabetic subjects $(76,105)$, but, to date, training has been reported to have no effect on MCT4 content. This indicates a difference in the regulation of MCT1 and MCT4 with pathology and contractile activity. However, in type 2 diabetic patients, a 10 -wk individualized training program, targeted at the power at which the highest rate of lipids are oxidized (LIPOXmax), did not change either MCT1 or MCT4 content (Metz L, Lambert K, Bordenave S, Mercier J., unpublished data). In contrast, in a type 1 diabetic rodent model, the reduction in the content of both MCT1 and MCT4 was alleviated by endurance treadmill training (42).

Time course studies are required to determine whether exercise training induces an increase or has no effect in MCT1 and MCT4 content in diabetic subjects (76) or whether exercise training prevents the continued decrease in MCT1 and MCT4 [as observed in sedentary control animals (42)]. Furthermore, the coupled effects of caloric restriction and training on skeletal muscle MCT content in humans, with and without insulin resistance, warrant further research. In addition, on the basis of previous studies, training can alter lactate transport capacity and MCT content, even when a skeletal muscle insulin resistant state exists. Zucker and STZ rats present "classical" sarcolemmal lactate transport adaptations to training, even though they present large differences in insulin levels. These results suggest that variations in MCT content and lactate transport are independent of insulin levels and that insulin state does not influence adaptations to training.

Inhibition of the calcineurin pathway is another factor related to contractile activity, which may affect MCT expression. Indeed, the serine/threonine phosphatase calcineurin plays a functional role in the hypertrophy and regeneration of skeletal muscle (134). It has been reported that a specific inhibitor of calcineurin by the administration of cyclosporine A increased MCT1 and MCT4 contents only in rat oxidative muscles, which suggests that calcineurin negatively regulates MCT contents with a fiber specificity (142).

Lactate as a cell-signaling molecule. In the only study to date, Hashimoto et al. (61) provided evidence that lactate formation may be a signal transduced to generate changes in MCT content in skeletal muscles. To examine this possibility, they used cultured L6 cells and chronically exposed these cells to high lactate levels (10 and $20 \mathrm{mM}$ ), similar to those found in muscles during high-intensity exercise. Hashimoto et al. (61) reported that after $1 \mathrm{~h}$ of incubation with lactate, there was increased mRNA and protein expression of MCT1, but not MCT4. Furthermore, CD147, a protein chaperone that facilitates the cell surface expression and the intrinsic activity of both MCT1 $(58,75,81,151)$ and MCT4 $(58,75,151)$, was also increased following $1 \mathrm{~h}$ of lactate incubation (61). These authors proposed that a transient increase in lactate concentration and mitochondrial oxygen consumption could generate reactive oxygen species (ROS), which would activate a transcriptional signaling network leading to adaptive cell responses (61). In this context, in response to exercise, ROS have been reported to phosphorylate both $\mathrm{p} 38 \mathrm{MAPK}$ and AMPK, which is also activated by alteration of the energy status, both of which activate peroxisome proliferator-activated receptor-)l coactivator (PGC)-1a (90) (Fig. 4).

Recent research suggests that MCT1 and CD147 belong to a family of metabolic genes whose expression is regulated by 
PGC-1a $(11,61)$. It has also been demonstrated by comparing oxidative capacities among muscles and by increasing muscle oxidative capacities by PGC-1a transfection and chronic muscle stimulation that there is a strong relationship between the expression of PGC-1a and MCT1, and between the expression of PGC-1a and CD147 proteins. Thus, in addition to being a metabolic intermediate, it has been proposed that lactate may also be a cell-signaling molecule, a "lactormone" (60), involving reactive oxygen species production, which can upregulate gene and protein expression [for review, see Brooks (26)].

However, one might ask why peak lactate concentration during training is not correlated with percentage changes in MCT content (Table 1), whereas in vitro study tends to demonstrate lactate as a cell-signaling molecule. Then, the peak value of lactatemia could not be the major factor of increase in MCT, but rather the changes in hyperlactatemia, and concomitantly in redox status and ROS during and after exercise. Acute repeated changes in glycolytic $\mathrm{fl}$ and metabolites concentration in skeletal muscles could affect MCT expression and transport activity, and chronic hyperlac- tatemia associated with metabolic disturbances could lead to a downregulation of MCT content and activity. Further study is required to determine the different cellular and molecular factors involved in MCT1 and MCT4 expression in humans in response to chronic contractile activity.

\section{Relationship Between Alteration of MCT Content and Lactate Transport Capacity}

An important unresolved question is whether or not MCT content and lactate transport capacity are independently regulated in response to acute and chronic exercise. Initial studies reported that the rate of lactate flux into and out of the skeletal muscle was correlated with the content of MCT1 and MCT4 in the sarcolemmal membrane $(23,24,98,99)$. However, subsequent studies have shown a dissociation between changes in MCT content and lactate transport activity (Fig. 5). For example, lactate transport capacity has been reported to be altered without change in MCT content in response to hormonal
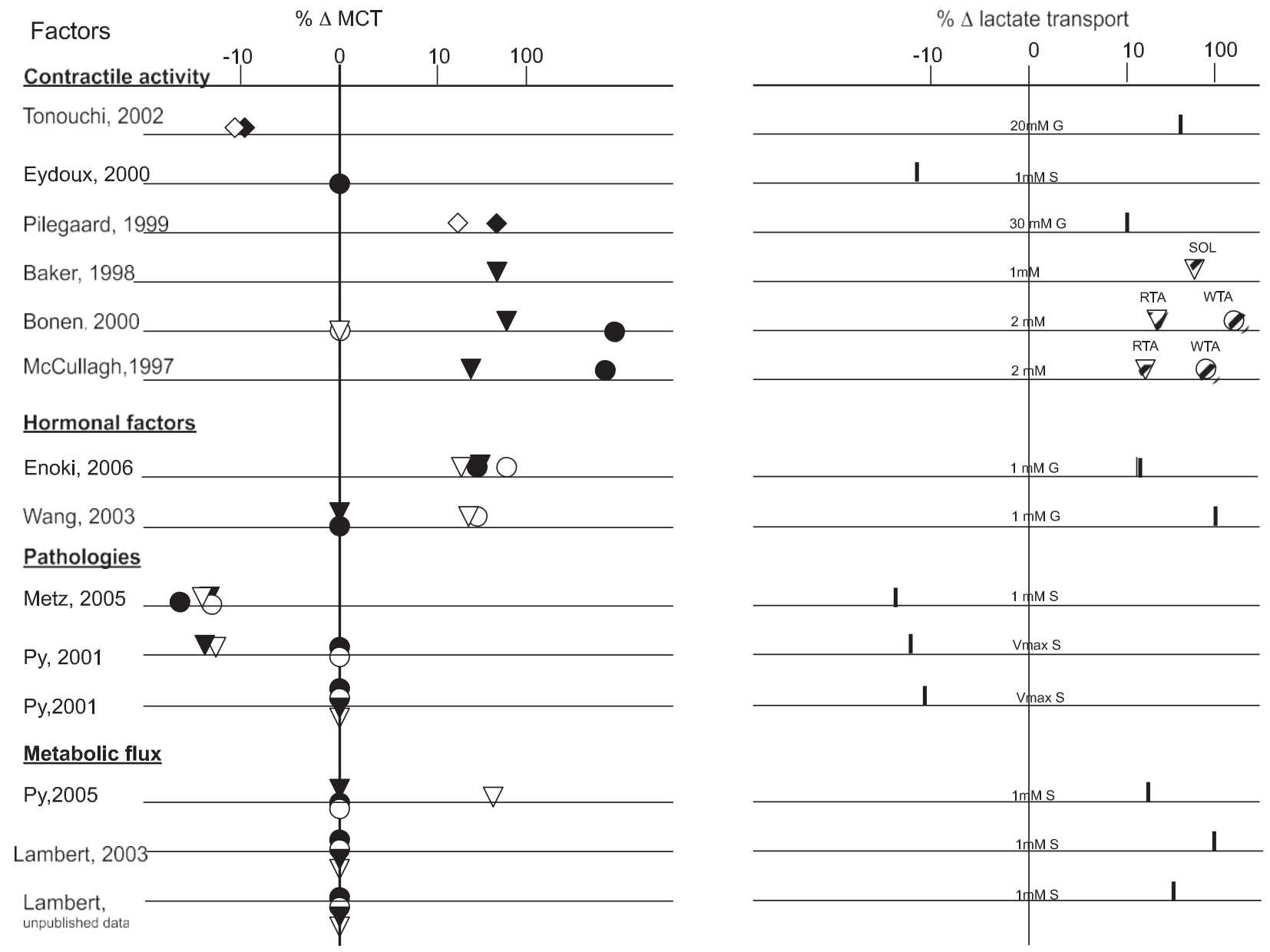

Fig. 5. Representation of MCT1 and MCT4 content (\% of control) in skeletal muscles or sarcolemmal vesicles and lactate transport capacity in muscle or in sarcolemmal vesicles using either giant (= G) or small (=S) vesicle. ", MCT1 in oxidative muscle; 6. MCT4 in oxidative muscle; e, MCT1 in glycolytic muscle; $\mathbb{E}$, MCT4in glycolytic muscle; , MCT1 when there is not muscle typology; (), MCT4 when there is not muscle typology; ${ }^{\nabla}$ denotes lactate transport measured in oxidative muscle; Clenotes lactate transport measured in glycolytic muscle; 1 denotes lactate transport measured in sarcolemmal muscles. Only studies that reported both MCT content and lactate-transport activity variations in response to contractile activity, hormonal factors, pathologies such as diabetes, and changes in metabolic fluxes are presented in this figure. \% MCT muscle denotes percentage change in MCT content measured in sarcolemmal membrane of skeletal muscle. \% lactate transport was measured in giant $(\mathrm{G})$ or sarcolemmal (S) vesicles, or in perfused or isolated rat muscles, at different concentrations of unlabeled L(+)-lactate $(1,2$, and $30 \mathrm{mM})$ or at the maximal rate of lactate influx $\left(V_{\max }\right)$. SOL, soleus muscle; RTA, red tibialis anterior muscle; WTA, white tibialis anterior muscle. 
factors (148), pathologies $(125,127)$, and changes in metabolic pathways (Lambert K, Thomas C, Metz L, Py G, Mercier J., unpublished data; 124). Regrettably, the literature contains few reports on the effects of exercise and exercise training on blood lactate flux, lactate oxidation, or tissue exchange.

Although some studies have observed that changes in MCT content in response to training seem to vary in parallel with changes in the lactate transport capacity $(21,39,77,116)$, some have not $(46,145)$. A possible explanation for this last observation could be a change in the intrinsic activity of MCT, as has been reported for GLUT4 activity (50). This latter mechanism could explain why small increases in MCT content have been associated with large increases in lactate transport capacity and why decreases in MCT content have been associated with an increase in lactate exchange (Fig. 5). Thus, lactate transport capacity may be regulated independently of MCT content in the sarcolemmal membrane in response to different stimuli. However, from data presented in Fig. 5, altered metabolic demand associated with contractile activity by skeletal muscles could regulate MCT content and lactate/proton transport capacity. Indeed, it appears that increases in MCT1 and MCT4 content with training may result from increases in contractile activity, whereas increase in lactate transport capacity may result from changes in metabolic pathways.

MCT1 and MCT4 proteins are important, since these isoforms participate in the cell-to-cell lactate shuttle, to transport both lactate, as a metabolic intermediary, and protons to counteract muscle acidosis. According to the different results reported in the literature, it appears that high-intensity interval training should be recommended to improve lactate transport capacity $(3,71,77,115,116)$, whereas high training volume is also necessary $\left(\dot{\mathrm{V}}_{\mathrm{O}_{2} \max }\right.$ superior to $\left.60 \mathrm{ml} \cdot \mathrm{min}^{1} \cdot \mathrm{kg}^{1}\right)$. Indeed, with acute repeated high-intensity training session, concomitant increases in contractile activity and lactate concentration may promote increases in MCT content, and changes in metabolic fluxes with high-intensity exercise and/or nutrition may contribute to an elevated lactate transport activity. These hypotheses need to be confirmed, along with the suggestion that the exercise-induced beneficial effects of ROS in muscle MCT expression should not be counteracted by taking antioxidants during training periods (122). Further research is required to determine the isoform-specific regulation of transporters, and the beneficial effect of ROS, as this has important implications for the design of interventions to improve these proteins in both health and disease.

\section{Conclusions}

It is clear that MCTs are important for regulating muscle $\mathrm{pH}$ and facilitating lactate exchange. Thus, MCTs play significant roles in the coordination of metabolism within and among tissues. During the last decade, interest has focused on the effects of acute and chronic exercise on the muscle content of these two isoforms. Despite limited research, it appears that both MCT1 and MCT4 belong to a class of proteins that can be rapidly altered by an acute bout of exercise. Further studies are needed to investigate the underlying mechanisms and to clarify the role of transcriptional regulation on the expression of these proteins in response to exercise. Such research has important implications for the design of an acute exercise stimulus to maximally increase MCT content.
The content of MCT1 and MCT4 in humans can also be affected by chronic activity levels, as indicated by the results of both cross-sectional and longitudinal studies. The type of training appears to be of little importance, as few studies have not observed an increase in MCT content or lactate transport capacity following training. However, further research is still required to determine the optimal intensity and duration of a training session to promote improvements in both MCT content and lactate transport capacity, although high-intensity appears to be more effective.

\section{Perspectives and Significance}

Further research is also required to confirm our observation that MCT1 protein expression is more sensitive to training than MCT4 protein expression. Once again, methodological limitations (and variations) limit the conclusions that can be drawn from the current literature. In particular, we note that the timing of the posttraining biopsy has not been standardized and that the smallest changes in MCT content are likely to be observed when the posttraining biopsy is performed close to the last training session. Finally, further studies are also needed to investigate the mechanisms responsible for increases in MCT content and lactate transport capacity in response to exercise training. Results of cross-sectional and longitudinal training studies show that like other important parameters of metabolism (e.g., $\dot{\mathrm{V}}_{\mathrm{O}_{2} \max }$, muscle mitochondrial density, or GLUT4 expression), muscle MCT expression is one among many factors affecting physical performance.

\section{REFERENCES}

1. Alvarez BV, Loiselle FB, Supuran CT, Schwartz GJ, Casey JR. Direct extracellular interaction between carbonic anhydrase IV and the human NBC1 sodium/bicarbonate co-transporter. Biochemistry 42: 12321-12329, 2003.

2. Arany Z, Foo SY, Ma Y, Ruas JL, Bommi-Reddy A, Girnun G, Cooper M, Laznik D, Chinsomboon J, Rangwala SM, Baek KH, Rosenzweig A, Spiegelman BM. HIF-independent regulation of VEGF and angiogenesis by the transcriptional coactivator PGC-1alpha. Nature 451: 1008-1012, 2008.

3. Baker SK, McCullagh KJ, Bonen A. Training intensity-dependent and tissue-specific increases in lactate uptake and MCT-1 in heart and muscle. J Appl Physiol 84: 987-994, 1998.

4. Barreiro E, Hussain SN. Protein carbonylation in skeletal muscles: impact on function. Antioxid Redox Signal 12: 417-429, 2010.

5. Becker HM, Broer S, Deitmer JW. Facilitated lactate transport by MCT1 when coexpressed with the sodium bicarbonate cotransporter (NBC) in Xenopus oocytes. Biophys J 86: 235-247, 2004.

6. Becker HM, Deitmer JW. Carbonic anhydrase II increases the activity of the human electrogenic $\mathrm{Na}^{+} / \mathrm{HCO}_{3}$-cotransporter. J Biol Chem 282: 13508-13521, 2007.

7. Becker HM, Hirnet D, Fecher-Trost C, Sultemeyer D, Deitmer JW. Transport activity of MCT1 expressed in Xenopus oocytes is increased by interaction with carbonic anhydrase. J Biol Chem 280: 39882-39889, 2005.

8. Becker HM, Klier M, Deitmer JW. Nonenzymatic augmentation of lactate transport via monocarboxylate transporter isoform 4 by carbonic anhydrase II. J Membr Biol 234: 125-135, 2010.

9. Bentley DJ, Roels B, Thomas C, Ives R, Mercier J, Millet G, Cameron-Smith D. The relationship between monocarboxylate transporters 1 and 4 expression in skeletal muscle and endurance performance in athletes. Eur J Appl Physiol 106: 465-471, 2009.

10. Benton CR, Campbell SE, Tonouchi M, Hatta H, Bonen A. Monocarboxylate transporters in subsarcolemmal and intermyofibrillar mitochondria. Biochem Biophys Res Commun 323: 249-253, 2004.

11. Benton CR, Yoshida Y, Lally J, Han XX, Hatta H, Bonen A. PGC-1alpha increases skeletal muscle lactate uptake by increasing the 
expression of MCT1 but not MCT2 or MCT4. Physiol Genomics 35: 45-54, 2008.

12. Bergman BC, Horning MA, Casazza GA, Wolfel EE, Butterfield GE, Brooks GA. Endurance training increases gluconeogenesis during rest and exercise in men. Am J Physiol Endocrinol Metab 278: E244 -E251, 2000.

13. Bergman BC, Wolfel EE, Butterfield GE, Lopaschuk GD, Casazza GA, Horning MA, Brooks GA. Active muscle and whole body lactate kinetics after endurance training in men. J Appl Physiol 87: 1684 -1696, 1999.

14. Bickham DC, Bentley DJ, Le Rossignol PF, Cameron-Smith D. The effects of short-term sprint training on MCT expression in moderately endurance-trained runners. Eur J Appl Physiol 96: 636-643, 2006.

15. Bigard AX, Douce P, Merino D, Lienhard F, Guezennec CY. Changes in dietary protein intake fail to prevent decrease in muscle growth induced by severe hypoxia in rats. J Appl Physiol 80: 208-215, 1996.

16. Bishop D, Edge J, Mendez-Villanueva A, Thomas C, Schneiker K. High-intensity exercise decreases muscle buffer capacity via a decrease in protein buffering in human skeletal muscle. Pflügers Arch 458: 929-936, 2009.

17. Bishop D, Edge J, Thomas C, Mercier J. Effects of high-intensity training on muscle lactate transporters and postexercise recovery of muscle lactate and hydrogen ions in women. Am J Physiol Regul Integr Comp Physiol 295: R1991-R1998, 2008.

18. Bishop D, Edge J, Thomas C, Mercier J. High-intensity exercise acutely decreases the membrane content of MCT1 and MCT4 and buffer capacity in human skeletal muscle. J Appl Physiol 102: 616-621, 2007.

19. Bonen A. The expression of lactate transporters (MCT1 and MCT4) in heart and muscle. Eur J Appl Physiol 86: 6-11, 2001.

20. Bonen A, Baker SK, Hatta H. Lactate transport and lactate transporters in skeletal muscle. Can J Appl Physiol 22: 531-552, 1997.

21. Bonen A, McCullagh KJ, Putman CT, Hultman E, Jones NL, Heigenhauser GJ. Short-term training increases human muscle MCT1 and femoral venous lactate in relation to muscle lactate. Am J Physiol Endocrinol Metab 274: E102-E107, 1998.

22. Bonen A, McDermott JC, Tan MH. Glycogenesis and glyconeogenesis in skeletal muscle: effects of $\mathrm{pH}$ and hormones. Am J Physiol Endocrinol Metab 258: E693-E700, 1990.

23. Bonen A, Miskovic D, Tonouchi M, Lemieux K, Wilson MC, Marette A, Halestrap AP. Abundance and subcellular distribution of MCT1 and MCT4 in heart and fast-twitch skeletal muscles. Am J Physiol Endocrinol Metab 278: E1067-E1077, 2000.

24. Bonen A, Tonouchi M, Miskovic D, Heddle C, Heikkila JJ, Halestrap AP. Isoform-specific regulation of the lactate transporters MCT1 and MCT4 by contractile activity. Am J Physiol Endocrinol Metab 279: E1131-E1138, 2000.

25. Broer S, Broer A, Schneider HP, Stegen C, Halestrap AP, Deitmer JW. Characterization of the high-affinity monocarboxylate transporter MCT2 in Xenopus laevis oocytes. Biochem J 341: 529-535, 1999.

26. Brooks GA. Cell-cell and intracellular lactate shuttles. $J$ Physiol 587: 5591-5600, 2009.

27. Brooks GA. Intra- and extra-cellular lactate shuttles. Med Sci Sports Exerc 32: 790-799, 2000.

28. Brooks GA. Lactate production under fully aerobic conditions: the lactate shuttle during rest and exercise. Fed Proc 45: 2924-2929, 1986.

29. Brooks GA. Lactate shuttles in nature. Biochem Soc Trans 30: 258 -264, 2002.

30. Brown MA, Brooks GA. Trans-stimulation of lactate transport from rat sarcolemmal membrane vesicles. Arch Biochem Biophys 313: 22-28, 1994.

31. Burgomaster KA, Cermak NM, Phillips SM, Benton CR, Bonen A, Gibala MJ. Divergent response of metabolite transport proteins in human skeletal muscle after sprint interval training and detraining. Am J Physiol Regul Integr Comp Physiol 292: R1970-R1976, 2007.

32. Burgomaster KA, Hughes SC, Heigenhauser GJ, Bradwell SN, Gibala MJ. Six sessions of sprint interval training increases muscle oxidative potential and cycle endurance capacity in humans. J Appl Physiol 98: 1985-1990, 2005.

33. Chwalbinska-Moneta J, Robergs RA, Costill DL, Fink WJ. Threshold for muscle lactate accumulation during progressive exercise. J Appl Physiol 66: 2710-2716, 1989.

34. Clarke SJ, Khaliulin I, Das M, Parker JE, Heesom KJ, Halestrap AP. Inhibition of mitochondrial permeability transition pore opening by ischemic preconditioning is probably mediated by reduction of oxidative stress rather than mitochondrial protein phosphorylation. Circ Res 102: 1082-1090, 2008.

35. Coles L, Litt J, Hatta H, Bonen A. Exercise rapidly increases expression of the monocarboxylate transporters MCT1 and MCT4 in rat muscle. J Physiol 561: 253-261, 2004.

36. Davies KJ, Quintanilha AT, Brooks GA, Packer L. Free radicals and tissue damage produced by exercise. Biochem Biophys Res Commun 107: 1198-1205, 1982.

37. Dimmer KS, Friedrich B, Lang F, Deitmer JW, Broer S. The lowaffinity monocarboxylate transporter MCT4 is adapted to the export of lactate in highly glycolytic cells. Biochem J 350: 219-227, 2000.

38. Donovan CM, Pagliassotti MJ. Quantitative assessment of pathways for lactate disposal in skeletal muscle fiber types. Med Sci Sports Exerc 32: $772-777,2000$.

39. Dubouchaud H, Butterfield GE, Wolfel EE, Bergman BC, Brooks GA. Endurance training, expression, and physiology of LDH, MCT1, and MCT4 in human skeletal muscle. Am J Physiol Endocrinol Metab 278: E571-E579, 2000.

40. Dubouchaud H, Eydoux N, Granier P, Prefaut C, Mercier J. Lactate transport activity in rat skeletal muscle sarcolemmal vesicles after acute exhaustive exercise. J Appl Physiol 87: 955-961, 1999.

41. Dubouchaud H, Granier P, Mercier J, Le Peuch C, Prefaut C. Lactate uptake by skeletal muscle sarcolemmal vesicles decreases after 4 wk of hindlimb unweighting in rats. J Appl Physiol 80: 416-421, 1996.

42. Enoki T, Yoshida Y, Hatta H, Bonen A. Exercise training alleviates MCT1 and MCT4 reductions in heart and skeletal muscles of STZinduced diabetic rats. J Appl Physiol 94: 2433-2438, 2003.

43. Enoki T, Yoshida Y, Lally J, Hatta H, Bonen A. Testosterone increases lactate transport, monocarboxylate transporter (MCT) 1 and MCT4 in rat skeletal muscle. J Physiol 577: 433-443, 2006.

44. Evertsen F, Medbo JI, Bonen A. Effect of training intensity on muscle lactate transporters and lactate threshold of cross-country skiers. Acta Physiol Scand 173: 195-205, 2001.

45. Eydoux N, Dubouchaud H, Py G, Granier P, Prefaut C, Mercier J. Lactate transport in rat sarcolemmal vesicles after a single bout of submaximal exercise. Int J Sports Med 21: 393-399, 2000.

46. Eydoux N, Py G, Lambert K, Dubouchaud H, Prefaut C, Mercier J. Training does not protect against exhaustive exercise-induced lactate transport capacity alterations. Am J Physiol Endocrinol Metab 278: E1045-E1052, 2000.

47. Fournier PA, Brau L, Ferreira LD, Fairchild T, Raja G, James A, Palmer TN. Glycogen resynthesis in the absence of food ingestion during recovery from moderate or high intensity physical activity: novel insights from rat and human studies. Comp Biochem Physiol A Mol Integr Physiol 133: 755-763, 2002.

48. Freund H, Oyono-Enguelle S, Heitz A, Marbach J, Ott C, Zouloumian P, Lampert E. Work rate-dependent lactate kinetics after exercise in humans. J Appl Physiol 61: 932-939, 1986.

49. Friedlander AL, Casazza GA, Horning MA, Huie MJ, Brooks GA. Training-induced alterations of glucose flux in men. J Appl Physiol 82: 1360-1369, 1997.

50. Furtado M, Poon V, Klip A. GLUT4 activation: thoughts on possible mechanisms. Acta Physiol Scand 178: 287-296, 2003.

51. Garcia CK, Goldstein JL, Pathak RK, Anderson RG, Brown MS. Molecular characterization of a membrane transporter for lactate, pyruvate, and other monocarboxylates: implications for the Cori cycle. Cell 76: 865-873, 1994.

52. Geers C, Gros G. Carbon dioxide transport and carbonic anhydrase in blood and muscle. Physiol Rev 80: 681-715, 2000.

53. Gertz EW, Wisneski JA, Stanley WC, Neese RA. Myocardial substrate utilization during exercise in humans. Dual carbon-labeled carbohydrate isotope experiments. J Clin Invest 82: 2017-2025, 1988.

54. Gladden LB. Lactate metabolism: a new paradigm for the third millennium. J Physiol 558: 5-30, 2004.

55. Green H, Halestrap A, Mockett C, O'Toole D, Grant S, Ouyang J. Increases in muscle MCT are associated with reductions in muscle lactate after a single exercise session in humans. Am J Physiol Endocrinol Metab 282: E154-E160, 2002.

56. Green HJ, Duhamel TA, Holloway GP, Moule JW, Ranney DW, Tupling AR, Ouyang J. Rapid upregulation of GLUT-4 and MCT-4 expression during $16 \mathrm{~h}$ of heavy intermittent cycle exercise. Am J Physiol Regul Integr Comp Physiol 294: R594-R600, 2008. 
57. Halestrap AP, Denton RM. Specific inhibition of pyruvate transport in rat liver mitochondria and human erythrocytes by alpha-cyano-4-hydroxycinnamate. Biochem J 138: 313-316, 1974.

58. Halestrap AP, Meredith D. The SLC16 gene family-from monocarboxylate transporters (MCTs) to aromatic amino acid transporters and beyond. Pflügers Arch 447: 619-628, 2004.

59. Hargreaves M, McKenna MJ, Jenkins DG, Warmington SA, Li JL, Snow RJ, Febbraio MA. Muscle metabolites and performance during high-intensity, intermittent exercise. J Appl Physiol 84: 1687-1691, 1998.

60. Hashimoto T, Brooks GA. Mitochondrial lactate oxidation complex and an adaptive role for lactate production. Med Sci Sports Exerc 40: 486-494, 2008.

61. Hashimoto T, Hussien R, Oommen S, Gohil K, Brooks GA. Lactate sensitive transcription factor network in L6 cells: activation of MCT1 and mitochondrial biogenesis. FASEB J 21: 2602-2612, 2007.

62. Hirche H, Grun D, Waller W. Utilization of carbohydrates and free fatty acids by the gastrocnemius of the dog during long lasting rhythmical exercise. Pflügers Arch 321: 121-132, 1970.

63. Hogan MC, Gladden LB, Kurdak SS, Poole DC. Increased [lactate] in working dog muscle reduces tension development independent of $\mathrm{pH}$. Med Sci Sports Exerc 27: 371-377, 1995.

64. Hultman E, Sahlin K. Acid-base balance during exercise. Exerc Sport Sci Rev 8: 41-128, 1980.

65. Johannsson E, Lunde PK, Heddle C, Sjaastad I, Thomas MJ, Bergersen L, Halestrap AP, Blackstad TW, Ottersen OP, Sejersted OM. Upregulation of the cardiac monocarboxylate transporter MCT1 in a rat model of congestive heart failure. Circulation 104: 729-734, 2001.

66. Jorfeldt L. Metabolism of L(plus)-lactate in human skeletal muscle during exercise. Acta Physiol Scand Suppl 338: 1-67, 1970.

67. Juel C. Intracellular $\mathrm{pH}$ recovery and lactate efflux in mouse soleus muscles stimulated in vitro: the involvement of sodium/proton exchange and a lactate carrier. Acta Physiol Scand 132: 363-371, 1988

68. Juel C. Lactate-proton cotransport in skeletal muscle. Physiol Rev 77: 321-358, 1997.

69. Juel C. Lactate/proton co-transport in skeletal muscle: regulation and importance for $\mathrm{pH}$ homeostasis. Acta Physiol Scand 156: 369-374, 1996.

70. Juel C. Muscle lactate transport studied in sarcolemmal giant vesicles. Biochim Biophys Acta 1065: 15-20, 1991.

71. Juel C. Muscle pH regulation: role of training. Acta Physiol Scand 162 359-366, 1998.

72. Juel C. Regulation of cellular $\mathrm{pH}$ in skeletal muscle fiber types, studied with sarcolemmal giant vesicles obtained from rat muscles. Biochim Biophys Acta 1265: 127-132, 1995.

73. Juel C. Symmetry and pH dependency of the lactate/proton carrier in skeletal muscle studied with rat sarcolemmal giant vesicles. Biochim Biophys Acta 1283: 106-110, 1996.

74. Juel C. Training-induced changes in membrane transport proteins of human skeletal muscle. Eur J Appl Physiol 96: 627-635, 2006.

75. Juel C, Halestrap AP. Lactate transport in skeletal muscle-role and regulation of the monocarboxylate transporter. J Physiol 517: 633-642, 1999.

76. Juel C, Holten MK, Dela F. Effects of strength training on muscle lactate release and MCT1 and MCT4 content in healthy and type 2 diabetic humans. J Physiol 556: 297-304, 2004.

77. Juel C, Klarskov C, Nielsen JJ, Krustrup P, Mohr M, Bangsbo J. Effect of high-intensity intermittent training on lactate and $\mathrm{H}^{+}$release from human skeletal muscle. Am J Physiol Endocrinol Metab 286: E245-E251, 2004.

78. Juel C, Kristiansen S, Pilegaard H, Wojtaszewski J, Richter EA. Kinetics of lactate transport in sarcolemmal giant vesicles obtained from human skeletal muscle. J Appl Physiol 76: 1031-1036, 1994.

79. Juel C, Lundby C, Sander M, Calbet JA, Hall G. Human skeletal muscle and erythrocyte proteins involved in acid-base homeostasis: adaptations to chronic hypoxia. J Physiol 548: 639-648, 2003.

80. Juel C, Pilegaard H. Lactate $/ \mathrm{H}^{+}$transport kinetics in rat skeletal muscle related to fibre type and changes in transport capacity. Pflügers Arch 436: 560-564, 1998.

81. Kirk P, Wilson MC, Heddle C, Brown MH, Barclay AN, Halestrap AP. CD147 is tightly associated with lactate transporters MCT1 and MCT4 and facilitates their cell surface expression. EMBO J 19: $3896-$ 3904, 2000 .
82. Kristensen JM, Kristensen M, Juel C. Expression of $\mathrm{Na}^{+} / \mathrm{HCO}^{\mathrm{cg}-}$ transporter proteins (NBCs) in rat and human skeletal muscle. Acta Physiol Scand 182: 69-76, 2004.

83. Kristensen M, Albertsen J, Rentsch M, Juel C. Lactate and force production in skeletal muscle. J Physiol 562: 521-526 2004.

84. Krustrup P, Mohr M, Amstrup T, Rysgaard T, Johansen J, Steensberg A, Pedersen PK, Bangsbo J. The yo-yo intermittent recovery test: physiological response, reliability, and validity. Med Sci Sports Exerc 35: 697-705, 2003.

85. Krustrup P, Mohr M, Nybo L, Jensen JM, Nielsen JJ, Bangsbo J. The Yo-Yo IR2 test: physiological response, reliability, and application to elite soccer. Med Sci Sports Exerc 38: 1666-1673, 2006.

86. Krustrup P, Soderlund K, Mohr M, Bangsbo J. The slow component of oxygen uptake during intense, sub-maximal exercise in man is associated with additional fibre recruitment. Pflügers Arch 447: 855-866, 2004.

87. Lamb GD, Stephenson DG, Bangsbo J, Juel C. Point:Counterpoint: Lactic acid accumulation is an advantage/disadvantage during muscle activity. J Appl Physiol 100: 1410-1412, 2006.

88. Lambert K, Py G, Eydoux N, Matecki S, Ramonatxo M, Prefaut C, Mercier J. Effect of food restriction on lactate sarcolemmal transport. Metabolism 52: 322-327, 2003.

90. Lira VA, Benton CR, Yan Z, Bonen A. PGC-1alpha regulation by exercise training and its influences on muscle function and insulin sensitivity. Am J Physiol Endocrinol Metab 299: E145-E161, 2010.

91. Lombardi AM, Fabris R, Bassetto F, Serra R, Leturque A, Federspil G, Girard J, Vettor R. Hyperlactatemia reduces muscle glucose uptake and GLUT-4 mRNA while increasing (E1a)PDH gene expression in rat. Am J Physiol Endocrinol Metab 276: E922-E929, 1999.

92. Marcinek DJ, Kushmerick MJ, Conley KE. Lactic acidosis in vivo: testing the link between lactate generation and $\mathrm{H}+$ accumulation in ischemic mouse muscle. J Appl Physiol 108: 1479-1486, 2010.

93. Mason MJ, Thomas RC. A microelectrode study of the mechanisms of L-lactate entry into and release from frog sartorius muscle. J Physiol 400: 459-479, 1988.

94. McClelland GB, Brooks GA. Changes in MCT1, MCT4, and LDH expression are tissue specific in rats after long-term hypobaric hypoxia. J Appl Physiol 92: 1573-1584, 2002.

95. McClelland GB, Khanna S, Gonzalez GF, Butz CE, Brooks GA. Peroxisomal membrane monocarboxylate transporters: evidence for a redox shuttle system? Biochem Biophys Res Commun 304: 130-135, 2003.

96. McCullagh KJ, Bonen A. Reduced lactate transport in denervated rat skeletal muscle. Am J Physiol Regul Integr Comp Physiol 268: R884R888, 1995.

97. McCullagh KJ, Juel C, O'Brien M, Bonen A. Chronic muscle stimulation increases lactate transport in rat skeletal muscle. Mol Cell Biochem 156: 51-57, 1996.

98. McCullagh KJ, Poole RC, Halestrap AP, O'Brien M, Bonen A. Role of the lactate transporter (MCT1) in skeletal muscles. Am J Physiol Endocrinol Metab 271: E143-E150, 1996.

99. McCullagh KJ, Poole RC, Halestrap AP, Tipton KF, O'Brien M, Bonen A. Chronic electrical stimulation increases MCT1 and lactate uptake in red and white skeletal muscle. Am J Physiol Endocrinol Metab 273: E239-E246, 1997.

100. McDermott JC, Bonen A. Lactate transport in rat sarcolemmal vesicles and intact skeletal muscle, and after muscle contraction. Acta Physiol Scand 151: 17-28, 1994.

101. McLane JA, Holloszy JO. Glycogen synthesis from lactate in the three types of skeletal muscle. J Biol Chem 254: 6548-6553, 1979.

102. Merezhinskaya N, Fishbein WN. Monocarboxylate transporters: past, present, future. Histol Histopathol 24: 243-264, 2009.

103. Messonnier L, Kristensen M, Juel C, Denis C. Importance of $\mathrm{pH}$ regulation and lactate $/ \mathrm{H}^{+}$transport capacity for work production during supramaximal exercise in humans. J Appl Physiol 102: 1936 -1944, 2007.

105. Metz L, Vermaelen M, Lambert K, Broca C, Sirvent P, Raynaud E, Mercier J. Endurance training increases lactate transport in male Zucker falfa rats. Biochem Biophys Res Commun 331: 1338-1345, 2005.

106. Meyer C, Saar P, Soydan N, Eckhard M, Bretzel RG, Gerich J, Linn T. A potential important role of skeletal muscle in human counterregulation of hypoglycemia. J Clin Endocrinol Metab 90: 6244-6250, 2005.

107. Miller BF, Fattor JA, Jacobs KA, Horning MA, Navazio F, Lindinger MI, Brooks GA. Lactate and glucose interactions during rest and 
exercise in men: effect of exogenous lactate infusion. $J$ Physiol 544: 963-975, 2002.

108. Mohr M, Krustrup P, Nielsen JJ, Nybo L, Rasmussen MK, Juel C, Bangsbo J. Effect of two different intense training regimens on skeletal muscle ion transport proteins and fatigue development. Am J Physiol Regul Integr Comp Physiol 292: R1594-R1602, 2007.

109. Morris ME, Felmlee MA. Overview of the proton-coupled MCT (SLC16A) family of transporters: characterization, function and role in the transport of the drug of abuse gamma-hydroxybutyric acid. AAPS $J$ 10: 311-321, 2008.

110. Mujika I, Padilla S, Pyne D, Busso T. Physiological changes associated with the pre-event taper in athletes. Sports Med 34: 891-927, 2004.

111. Neary JP, Martin TP, Reid DC, Burnham R, Quinney HA. The effects of a reduced exercise duration taper programme on performance and muscle enzymes of endurance cyclists. Eur J Appl Physiol Occup Physiol 65: 30-36, 1992.

112. Nielsen OB, de Paoli F, Overgaard K. Protective effects of lactic acid on force production in rat skeletal muscle. J Physiol 536: 161-166, 2001.

113. Oyono-Enguelle S, Freund H, Lonsdorfer J, Pape A. Impaired lactate exchange and removal abilities after supramaximal exercise in humans. Med Sport Sci 34: 140-161, 1992.

114. Pedersen TH, Clausen T, Nielsen OB. Loss of force induced by high extracellular $\left[\mathrm{K}^{+}\right]$in rat muscle: effect of temperature, lactic acid and beta2-agonist. J Physiol 551: 277-286, 2003.

115. Pilegaard H, Bangsbo J, Richter EA, Juel C. Lactate transport studied in sarcolemmal giant vesicles from human muscle biopsies: relation to training status. J Appl Physiol 77: 1858-1862, 1994.

116. Pilegaard H, Domino K, Noland T, Juel C, Hellsten Y, Halestrap AP, Bangsbo J. Effect of high-intensity exercise training on lactate/ $\mathrm{H}^{+}$ transport capacity in human skeletal muscle. Am J Physiol Endocrinol Metab 276: E255-E261, 1999.

117. Pilegaard H, Juel C. Lactate transport studied in sarcolemmal giant vesicles from rat skeletal muscles: effect of denervation. Am J Physiol Endocrinol Metab 269: E679-E682, 1995.

118. Pilegaard H, Juel C, Wibrand F. Lactate transport studied in sarcolemmal giant vesicles from rats: effect of training. Am J Physiol Endocrinol Metab 264: E156-E160, 1993.

119. Pilegaard H, Terzis G, Halestrap A, Juel C. Distribution of the lactate $/ \mathrm{H}^{+}$transporter isoforms MCT1 and MCT4 in human skeletal muscle. Am J Physiol Endocrinol Metab 276: E843-E848, 1999.

120. Poole RC, Halestrap AP. Transport of lactate and other monocarboxylates across mammalian plasma membranes. Am J Physiol Cell Physiol 264: C761-C782, 1993

121. Poole RC, Halestrap AP, Price SJ, Levi AJ. The kinetics of transport of lactate and pyruvate into isolated cardiac myocytes from guinea pig. Kinetic evidence for the presence of a carrier distinct from that in erythrocytes and hepatocytes. Biochem J 264: 409-418, 1989.

122. Powers SK, Jackson MJ. Exercise-induced oxidative stress: cellular mechanisms and impact on muscle force production. Physiol Rev 88: 1243-1276, 2008.

123. Price NT, Jackson VN, Halestrap AP. Cloning and sequencing of four new mammalian monocarboxylate transporter (MCT) homologues confirms the existence of a transporter family with an ancient past. Biochem $J$ 329: 321-328, 1998.

124. Py G, Eydoux N, Lambert K, Chapot R, Koulmann N, Sanchez H, Bahi L, Peinnequin A, Mercier J, Bigard AX. Role of hypoxia-induced anorexia and right ventricular hypertrophy on lactate transport and MCT expression in rat muscle. Metabolism 54: 634-644, 2005.

125. Py G, Eydoux N, Perez-Martin A, Raynaud E, Brun JF, Prefaut C, Mercier J. Streptozotocin-induced diabetes decreases rat sarcolemmal lactate transport. Metabolism 50: 418-424, 2001

126. Py G, Lambert K, Milhavet O, Eydoux N, Prefaut C, Mercier J. Effects of streptozotocin-induced diabetes on markers of skeletal muscle metabolism and monocarboxylate transporter 1 to monocarboxylate transporter 4 transporters. Metabolism 51: 807-813, 2002.

127. Py G, Lambert K, Perez-Martin A, Raynaud E, Prefaut C, Mercier J. Impaired sarcolemmal vesicle lactate uptake and skeletal muscle MCT1 and MCT4 expression in obese Zucker rats. Am J Physiol Endocrinol Metab 281: E1308-E1315, 2001.

128. Robergs RA, Ghiasvand F, Parker D. Biochemistry of exerciseinduced metabolic acidosis. Am J Physiol Regul Integr Comp Physiol 287: R502-R516, 2004.
129. Roth DA, Brooks GA. Lactate and pyruvate transport is dominated by a $\mathrm{pH}$ gradient-sensitive carrier in rat skeletal muscle sarcolemmal vesicles. Arch Biochem Biophys 279: 386-394, 1990.

130. Roth DA, Brooks GA. Lactate transport is mediated by a membranebound carrier in rat skeletal muscle sarcolemmal vesicles. Arch Biochem Biophys 279: 377-385, 1990.

131. Roth DA, Brooks GA. Training does not affect zero-trans lactate transport across mixed rat skeletal muscle sarcolemmal vesicles. $J$ Appl Physiol 75: 1559-1565, 1993.

132. Roth SM, Ferrell RE, Peters DG, Metter EJ, Hurley BF, Rogers MA. Influence of age, sex, and strength training on human muscle gene expression determined by microarray. Physiol Genomics 10: 181-190, 2002.

133. Sahlin K. Metabolic factors in fatigue. Sports Med 13: 99-107, 1992.

134. Sakuma K, Yamaguchi A. The functional role of calcineurin in hypertrophy, regeneration, and disorders of skeletal muscle. J Biomed Biotechnol 2010: 721219, 2010.

135. Scheuermann BW, Kowalchuk JM, Paterson DH, Cunningham DA. Carbonic anhydrase inhibition delays plasma lactate appearance with no effect on ventilatory threshold. J Appl Physiol 88: 713-721, 2000.

136. Schmutz S, Dapp C, Wittwer M, Durieux AC, Mueller M, Weinstein F, Vogt M, Hoppeler H, Fluck M. A hypoxia complement differentiates the muscle response to endurance exercise. Exp Physiol 95: 723-735, 2010.

137. Sen CK. Oxidants and antioxidants in exercise. J Appl Physiol 79: 675686, 1995

138. Shepley B, MacDougall JD, Cipriano N, Sutton JR, Tarnopolsky MA, Coates G. Physiological effects of tapering in highly trained athletes. J Appl Physiol 72: 706-711, 1992.

139. Spangenburg EE, Ward CW, Williams JH. Effects of lactate on force production by mouse EDL muscle: implications for the development of fatigue. Can J Physiol Pharmacol 76: 642-648, 1998.

140. Spriet LL, Matsos CG, Peters SJ, Heigenhauser GJ, Jones NL. Effects of acidosis on rat muscle metabolism and performance during heavy exercise. Am J Physiol Cell Physiol 248: C337-C347, 1985.

141. Stanley WC, Gertz EW, Wisneski JA, Neese RA, Morris DL, Brooks GA. Lactate extraction during net lactate release in legs of humans during exercise. J Appl Physiol 60: 1116-1120, 1986.

142. Suwa M, Nakano H, Kumagai S. Inhibition of calcineurin increases monocarboxylate transporters 1 and 4 protein and glycolytic enzyme activities in rat soleus muscle. Clin Exp Pharmacol Physiol 32: 218 -223, 2005.

143. Thomas C, Bishop D, Moore-Morris T, Mercier J. Effects of highintensity training on MCT1, MCT4, and NBC expressions in rat skeletal muscles: influence of chronic metabolic alkalosis. Am J Physiol Endocrinol Metab 293: E916-E922, 2007.

144. Thomas C, Perrey S, Lambert K, Hugon G, Mornet D, Mercier J. Monocarboxylate transporters, blood lactate removal after supramaximal exercise, and fatigue indexes in humans. J Appl Physiol 98: 804-809, 2005.

145. Tonouchi M, Hatta H, Bonen A. Muscle contraction increases lactate transport while reducing sarcolemmal MCT4, but not MCT1. Am J Physiol Endocrinol Metab 282: E1062-E1069, 2002.

146. Trimmer JK, Schwarz JM, Casazza GA, Horning MA, Rodriguez N, Brooks GA. Measurement of gluconeogenesis in exercising men by mass isotopomer distribution analysis. J Appl Physiol 93: 233-241, 2002.

147. Ullah MS, Davies AJ, Halestrap AP. The plasma membrane lactate transporter MCT4, but not MCT1, is up-regulated by hypoxia through a HIF-1alpha-dependent mechanism. J Biol Chem 281: 9030-9037, 2006.

148. Wang Y, Tonouchi M, Miskovic D, Hatta H, Bonen A. T3 increases lactate transport and the expression of MCT4, but not MCT1, in rat skeletal muscle. Am J Physiol Endocrinol Metab 285: E622-E628, 2003.

149. Wetzel P, Hasse A, Papadopoulos S, Voipio J, Kaila K, Gros G. Extracellular carbonic anhydrase activity facilitates lactic acid transport in rat skeletal muscle fibres. $J$ Physiol 531: 743-756, 2001.

150. Wilson MC, Jackson VN, Heddle C, Price NT, Pilegaard H, Juel C, Bonen A, Montgomery I, Hutter OF, Halestrap AP. Lactic acid efflux from white skeletal muscle is catalyzed by the monocarboxylate transporter isoform MCT3. J Biol Chem 273: 15920-15926, 1998.

151. Wilson MC, Meredith D, Halestrap AP. Fluorescence resonance energy transfer studies on the interaction between the lactate transporter MCT1 and CD147 provide information on the topology and stoichiometry of the complex in situ. J Biol Chem 277: 3666-3672, 2002. 